\author{
UNIVERSIDADE DE SÃO PAULO \\ FACULDADE DE MEDICINA DE RIBEIRÃO PRETO \\ Programa de Pós-Graduação em Saúde Pública
}

BRUNA FREQUETE DE ALMEIDA SANTOS

Aplicabilidade e viabilidade do lavado broncoalveolar: análise retrospectiva de 1000 casos em hospital de referência de nível terciário

Ribeirão Preto - SP

2021 
BRUNA FREQUETE DE ALMEIDA SANTOS

\title{
Aplicabilidade e viabilidade do lavado broncoalveolar: análise retrospectiva de 1000 casos em hospital de referência de nível terciário
}

\author{
Versão corrigida
}

Dissertação apresentada ao Curso de PósGraduação stricto sensu, no nível mestrado, do Programa de Pós-graduação em Saúde Pública da Faculdade de Medicina de Ribeirão Preto - USP.

Área de concentração: Saúde Pública

Orientador: Elcio S. Oliveira Vianna

RIBEIRÃO PRETO - SP

2021 
Autorizo a reprodução e divulgação total ou parcial deste trabalho, por qualquer meio convencional ou eletrônico, para fins de estudo de pesquisa, desde que citada a fonte.

Santos, Bruna Frequete de Almeida

Aplicabilidade e viabilidade do lavado broncoalveolar: análise retrospectiva de 1000 casos em hospital de referência de nível terciário

77p.: il.

Tese de mestrado, apresentada à Faculdade de Medicina de Ribeirão Preto/USP - Área de concentração: Saúde Pública.

Orientador: Vianna, Elcio S. Oliveira

1. Lavado broncoalveolar. 2. Aplicabilidade. 3. Viabilidade. 4. Rendimento diagnóstico. 
SANTOS, Bruna Frequete de Almeida

Título: Aplicabilidade e viabilidade do lavado broncoalveolar: análise retrospectiva de 1000 casos em hospital de referência de nível terciário.

Dissertação apresentada à Faculdade de Medicina de Ribeirão Preto da Universidade de São Paulo, para obtenção do título de mestre em Saúde Pública.

Aprovado em:

\section{Banca examinadora}

Prof. Dr.:

Instituição:

Julgamento:

Assinatura:

Prof. Dr.:

Instituição:

Julgamento:

Assinatura:

Prof. Dr.:

Instituição:

Julgamento:

Assinatura: 


\section{AGRADECIMENTOS}

À Deus, por ter me proporcionado saúde e força para superar as minhas dificuldades.

Aos meus pais, pela dedicação e compreensão do meu caminhar e minhas ausências junto à família.

Ao meu Marido, que acima de tudo é um grande amigo e parceiro que sempre me apoiou nos momentos difíceis.

Ao Prof. Dr. Élcio dos Santos de Oliveira Vianna, pela oportunidade de crescimento pessoal e profissional e, principalmente pela ajuda e orientação na realização deste trabalho.

À Dra. Andrea de Cássia Vernier Antunes Cetlin, pela dedicação e ajuda com a pesquisa.

Aos funcionários do departamento de pneumologia, por tornar possível a realização desse trabalho.

Aos meus muitos professores, que com toda dedicação, me ajudaram nessa longa caminhada.

À Coordenação de Aperfeiçoamento de Pessoal de Nível Superior (CAPES), por saber o valor das pesquisas apoiando-as. 


\section{RESUMO}

SANTOS, B. F. A. Aplicabilidade e viabilidade do lavado broncoalveolar: análise retrospectiva de $\mathbf{1 0 0 0}$ casos em hospital de referência de nível terciário. 2021. Dissertação (Mestrado) - Faculdade de Medicina de Ribeirão Preto, Universidade de São Paulo, Ribeirão Preto, 2021.

O lavado broncoalveolar (LBA) é um exame que analisa o material alveolar obtido pela solução salina estéril injetada e em seguida coletada de um subsegmento pulmonar a ser investigado. Trata-se de um procedimento minimamente invasivo que visa a avaliação do parênquima pulmonar, com riscos baixos. Apesar da grande utilização desse exame em determinadas instituições hospitalares, há a preocupação em se manter o sistema de saúde sustentável a longo prazo, e técnicas de alta tecnologia que envolvem altos custos, precisam ter seus usos e suas indicações direcionadas. Os objetivos dessa pesquisa foram avaliar o impacto do LBA no tratamento dos pacientes do Hospital das Clínicas da Faculdade de Medicina de Ribeirão Preto (HCRP), conhecer a viabilidade da realização do LBA para direcionar suas indicações e proporcionar melhor aproveitamento do serviço de saúde e seus recursos. Para isso, foi realizado o levantamento através de pesquisa retrospectiva em prontuários médicos de mil indivíduos que realizaram LBA na Seção de Pneumologia do HCRP, sendo avaliadas as hipóteses diagnósticas, o seguimento clínico-terapêutico e a contribuição do LBA para resolução desses casos. Para a análise, foram utilizadas a estatística descritiva, cálculo de rendimento diagnóstico e teste ANOVA one-way com Tukey para pós-teste, sendo o valor de $p$ adotado $<0,05$ e intervalo de confiança de $95 \%$. Foi empregado o software SPSS Statistic 26 . Os casos foram divididos de acordo com suas as hipóteses diagnósticas, que foram tuberculoses, infecções fúngicas, infecções bacterianas e virais, neoplasias pulmonares, pneumonite de hipersensibilidade, doenças pulmonares intersticiais, sarcoidose, fibrose pulmonar e doenças ocupacionais. Como principais resultados, encontramos que $78,65 \%$ dos casos avaliados apresentaram uma ou mais comorbidades. O principal local de realização do LBA foi brônquio do lobo médio ( $26,2 \%$ dos casos), porém, o brônquio do lobo inferior esquerdo foi o que mais se diferenciou dos demais em relação ao seu volume de retorno após ser infundida a solução fisiológica, seguido pelo brônquio lobo médio, do lobo inferior direito e brônquio da língula. As complicações ocorreram em $2,5 \%$ dos casos, e o rendimento diagnóstico do LBA variou entre as hipóteses diagnósticas investigadas, com tuberculose, neoplasia, infecções fúngicas, pneumonite de hipersensibilidade e doença pulmonar intersticial com rendimentos diagnósticos de, respectivamente, 92,17\%, 3,23\%, 91,00\%, 90,23\% e $73,74 \%$. Ao final, no desfecho das investigações clínicas, $53,17 \%$ dos casos apresentaram mudanças nas suas condutas após a realização do LBA e, 86,34\% apresentaram efeito diagnóstico, contribuindo para a resolução dos casos. Concluímos que o LBA se afirma como um importante recurso para 0 auxílio diagnóstico e consequentemente, para a condução dos casos das doenças pesquisadas no atual trabalho, com destaque para os casos de infecções, indicando o LBA como exame seguro, viável e eficaz, otimizando-se os recursos da saúde.

Palavras-chave: Lavado broncoalveolar. Aplicabilidade. Viabilidade. Rendimento diagnóstico. 


\begin{abstract}
SANTOS, B. F. A. Bronchoalveolar lavage applicability and feasibility: retrospective analysis of $\mathbf{1 0 0 0}$ cases in a tertiary-level referral hospital. 2021. Dissertação (Mestrado) - Faculdade de Medicina de Ribeirão Preto, Universidade de São Paulo, Ribeirão Preto, 2021.

Bronchoalveolar lavage (BAL) is a test that analyzes alveolar material obtained from sterile saline solution that is injected and then collected from a pulmonary subsegment to be investigated. This is a minimally invasive procedure aimed at evaluating the lung parenchyma, with low risks. Despite the widespread use of this test in certain hospital institutions, there is a concern to keep the health system sustainable in the long term and high-tech techniques that involve high costs need to have their use and indication targeted. The objectives of this research were to evaluate the impact of LBA in the treatment of patients at the Hospital das Clínicas of the Faculty of Medicine of Ribeirão Preto (HCRP), to know the feasibility of carrying out LBA to direct its indications and provide better use of the health service and its resources. For this, the survey was carried out through a retrospective survey of medical records of one thousand individuals who underwent BAL in the Pneumology Section of the HCRP, evaluating the diagnostic hypotheses, the clinical-therapeutic follow-up and the contribution of $\mathrm{BAL}$ in the resolution of these cases. For the analysis, descriptive statistics, diagnostic yield calculation and one-way ANOVA test with Tukey for post-test were used, with $p$ value $<0.05$ and $95 \%$ confidence interval. The SPSS Statistic 26 software was used. The cases were divided according to their diagnostic hypotheses, which were tuberculosis, fungal infections, bacterial and viral infections, lung cancer, hypersensitivity pneumonitis, interstitial lung diseases, sarcoidosis, pulmonary fibrosis and occupational diseases. As main results, we found that $78.65 \%$ of the cases evaluated had one or more comorbidities. The main place of BAL performance was the middle lobe bronchus (26.2\% of the cases), however, the left lower lobe bronchus was the one that most differed from the others in relation to its return volume after the saline solution was infused, followed by the middle lobe bronchus, the right lower lobe bronchus and the lingula bronchus. Serious complications occurred in $2.5 \%$ of the cases, and the diagnostic yield of BAL varied between the investigated diagnostic hypotheses, with tuberculosis, neoplasm, fungal infections, hypersensitivity pneumonitis and interstitial lung disease with diagnostic yields of, respectively, 92.17 $\%, 3.23 \%, 91.00 \%, 90.23 \%$ and $73.74 \%$. In the end, in the outcome of the clinical investigations, $53.17 \%$ of the cases showed changes in their behavior after performing the BAL, and $86.34 \%$ showed a diagnostic effect, contributing to the resolution of the cases. We conclude that BAL is an important resource for diagnostic aid and, consequently, for the management of cases of the diseases researched in our work, with emphasis on cases of infections, indicating BAL as a safe, viable and effective test and optimizing the health resources.
\end{abstract}

Keywords: Bronchoalveolar lavage. Applicability. Viability. Diagnostic yield. 


\section{LISTA DE FIGURAS}

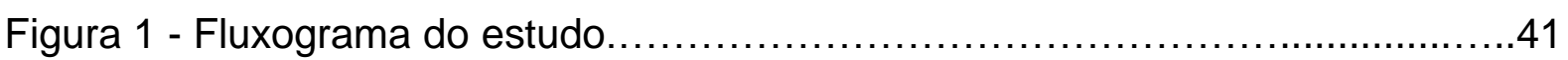

Figura 2 - Modelo de solicitação para realização do LBA.......................................75

Figura 3 - Modelo do banco de dados para inserção das variáveis dos indivíduos da

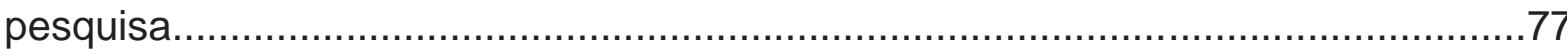




\section{LISTA DE TABELAS}

Tabela 1 - Dados gerais dos indivíduos submetidos à coleta de LBA

Tabela 2 - Hipóteses clínicas para indicação de LBA.

Tabela 3 - Situações da coleta do LBA

Tabela 4 - Localização pulmonar da coleta do LBA

Tabela 5 - Características técnicas do LBA por localização pulmonar 46

Tabela 6 - Comparações entre localizações pulmonares do LBA 46

Tabela 7 - Complicações decorrentes do procedimento de coleta do LBA

Tabela 8 - Contribuição da análise do LBA nas condutas médicas e efeitos diagnósticos.

Tabela 9 - Contribuição do LBA no diagnóstico de casos suspeitos de tuberculose. .49

Tabela 10 - Contribuição do LBA no diagnóstico de casos suspeitos de neoplasias.

Tabela 11 - Contribuição do LBA no diagnóstico de casos suspeitos de infecções fúngicas

Tabela 12 - Contribuição do LBA no diagnóstico de casos suspeitos de

$\mathrm{PH}$. .50

Tabela 13 - Contribuição do LBA no diagnóstico de casos suspeitos de DIP. .51 


\section{SUMÁRIO}

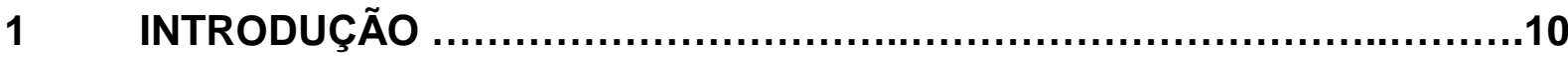

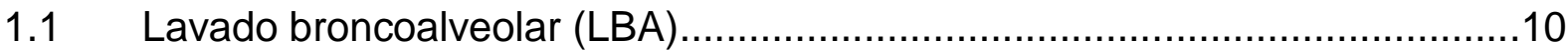

1.1.1 LBA e as doenças pulmonares intersticiais (DIPs) .....................................14

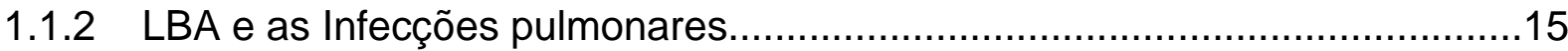

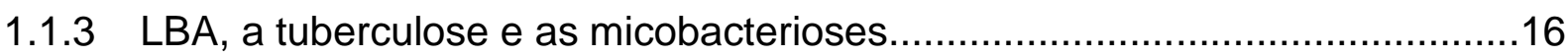

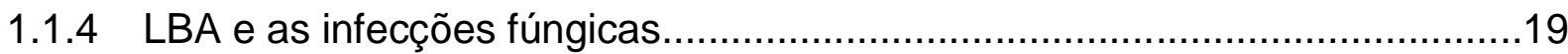

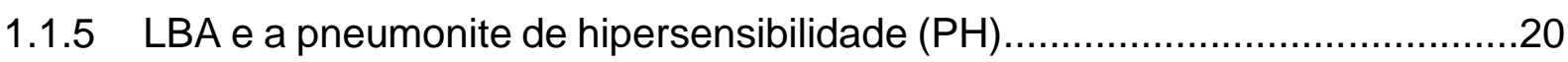

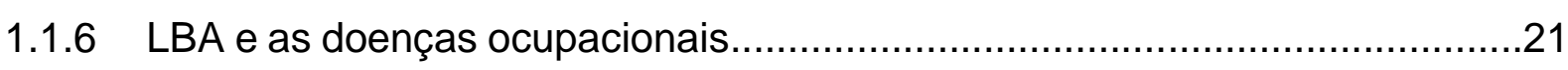

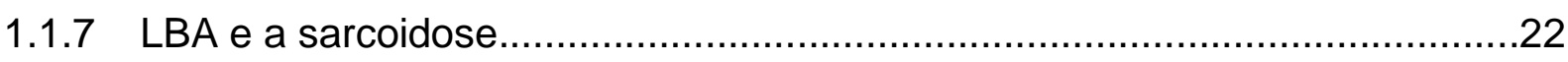

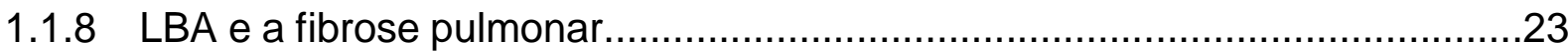

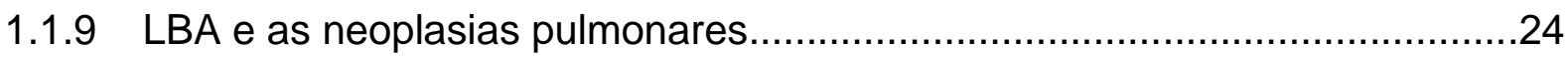

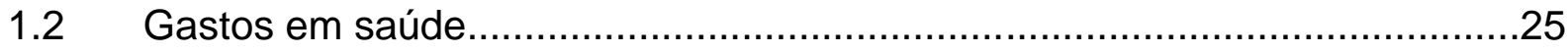

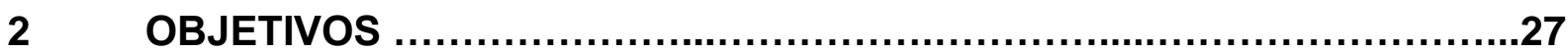

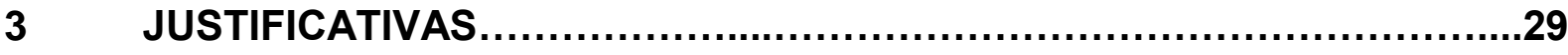

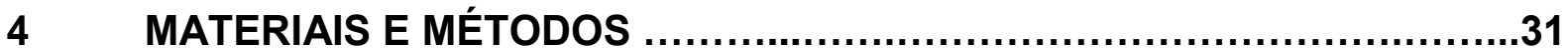

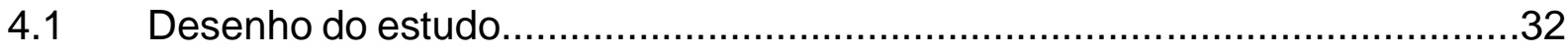

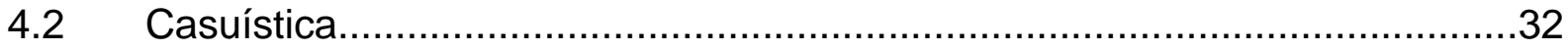

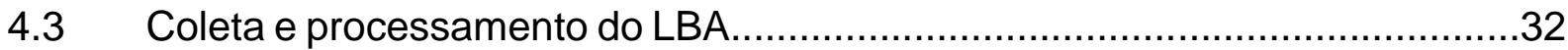

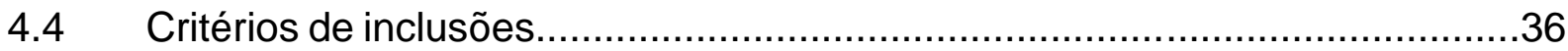

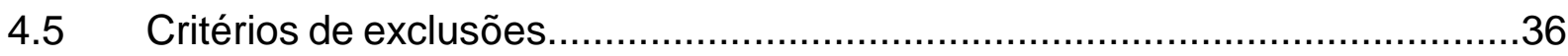

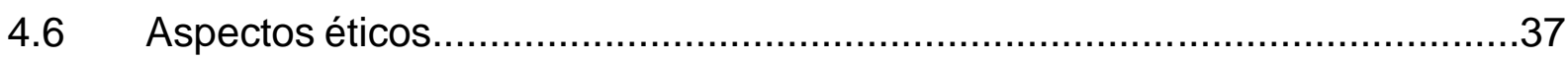

4.7 Condições orçamentárias da pesquisa......................................................

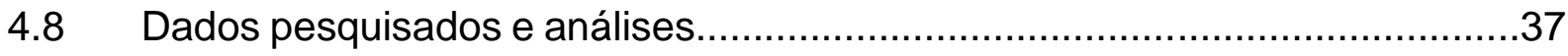

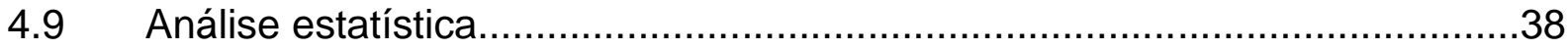

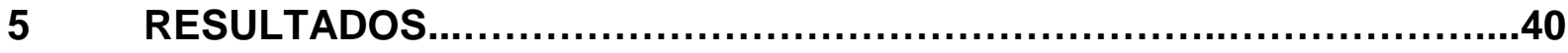

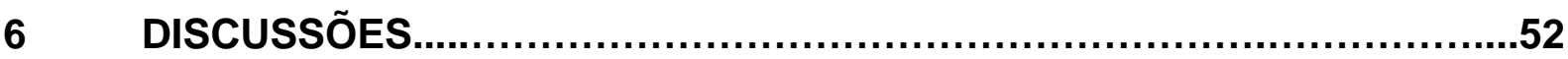

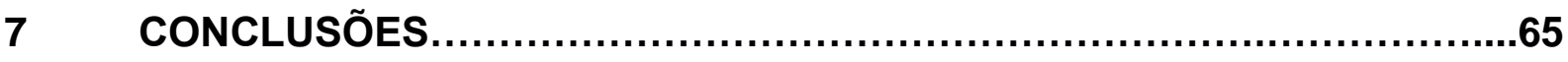

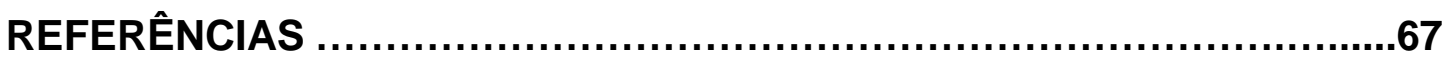

ANEXO A - Modelo de solicitação para realizações do LBA...................74

APÊNDICE A - Modelo do banco de dados para inserção das variáveis dos indivíduos da pesquisa......................................................... 
1 INTRODUÇÃO 


\subsection{Lavado broncoalveolar}

O lavado broncoalveolar (LBA) é um exame que analisa o material obtido pela instilação de solução salina estéril que, em seguida, é coletada de um subsegmento pulmonar a ser investigado. Trata-se de um procedimento minimamente invasivo, onde se utiliza um broncoscópio flexível até a área pulmonar do trato respiratório inferior, podendo também em algumas situações ser utilizada como prática terapêutica. Esse método visa a avaliação ao nível alveolar, onde é foco comum de uma grande parcela das doenças respiratórias. A coleta do LBA como é utilizada hoje foi popularizada em 1974 pelos médicos americanos Reynolds e Newball, em Maryland (PATEL; BHIMJI, 2017).

Trata-se de um procedimento realizado em conjunto com a broncoscopia seguida de preparação e análise das amostras obtidas, onde a análise da citologia do LBA reflete a composição celular dentro dos alvéolos, fazendo-se assim, investigação diagnóstica complementar de suspeitas de alterações patológicas pulmonares (FRYE et al., 2020).

Em relação à indicação, o LBA é mais comumente realizado por suspeitas infecções pulmonares. Em casos de infecção bacteriana o seu rendimento é maior que $70 \%$. Com a evolução nesse campo, o LBA ganhou força e destaque para investigações de infecções pulmonares com as novas técnicas microbiológicas como o antígeno galactomanano, beta-D-glucana e reação em cadeia de teste de polimerase para Pneumocystis carinii, Aspergillus e patógenos virais. Para o diagnóstico de Mycobacterium tuberculosis, a cultura do LBA detecta aproximadamente $75 \%$ dos casos e a adição de testes específicos de amplificação de ácidos nucleicos resulta em taxas ainda maiores de detecção. Seu uso também é comum na investigação de doença pulmonar parenquimatosa difusa. Dentro dos distúrbios lentamente progressivos, o lavado é usado principalmente para excluir etiologias infecciosas que possam imitar doença pulmonar intersticial. É mais útil na avaliação de pacientes com determinadas doenças em desenvolvimento; como pneumonias eosinofílicas agudas ou crônicas e proteinose alveolar. O LBA também é comumente utilizado como um complemento para outras modalidades de amostragem broncoscópica no diagnóstico de malignidade. Como um teste independente, o rendimento diagnóstico para cânceres periféricos é menor que 50\%. No entanto, em casos de linfangite carcinomatosa, o rendimento diagnóstico supera $80 \%$ (MILLER et al., 2018). 
A broncoscopia com LBA em conjunto com a análise molecular no diagnóstico e tratamento de infecções respiratórias pode servir como guia para o tratamento e pode modificar condutas dos pacientes submetidos (ILANA et al., 2016).

Atualmente a coleta do LBA não está padronizada, porém, a recomendação dos especialistas é de se manter o material que será coletado sem contaminações. $O$ líquido obtido deve ser misturado e ter seu volume registrado para ser enviado para o laboratório rapidamente ou deve ser armazenado no gelo para transportes demorados para se manter as células viáveis. Suas células serão quantificadas por meio de coloração (PATEL; BHIMJI, 2017).

Em situações em que a coleta do material do LBA não está guiada por exame de imagem, o local de escolha para o procedimento deve ser de preferência o lobo médio, isso devido ao fato de tal local estar associado a um aumento do retorno do líquido para a análise (RADHAKRISHNA et al., 2015). Essa informação também foi avaliada no presente estudo.

Algumas etapas são recomendadas para o LBA de acordo com a sua indicação, dentre elas, coletar o LBA antes da biópsia para minimizar a contaminação por sangue quando se pretende avaliar a citologia. Nesse caso, recomenda-se ainda descartar os 20 a $30 \mathrm{ml}$ iniciais do material aspirado para evitar-se a contaminação por material das superfícies brônquicas no conteúdo alveolar, porém, isso pode diminuir o rendimento diagnóstico (PATEL; BHIMJI, 2017).

A pesquisa laboratorial do fluido coletado pode detectar também a presença de ferro, células malignas, poeira inorgânica e microrganismos. Em caso de conter menos de 2 milhões de células totais ou menos de 10 macrófagos alveolares por campo de alta potência, ou um número elevado de glóbulos vermelhos (devido a trauma da via área durante a coleta do material) ou houver alterações degenerativas, a amostra pode estar comprometida e assim comprometer o diagnóstico (PATEL; BHIMJI, 2017).

Fatores externos precisam ser considerados para a análise, como é o caso do tabagismo. Em adultos fumantes, o número de células pode aumentar de 4 - 6 vezes, das quais a maioria são macrófagos (PATEL; BHIMJI, 2017).

Dentre as principais condições para a realização do LBA, estão infecções respiratórias oportunistas e atípicas em pacientes imunocomprometidos, infiltrados pulmonares radiográficos inexplicáveis ou hipoxemia, hemorragia alveolar difusa, proteinose alveolar pulmonar, pneumonia eosinofílica, pneumonite de 
hipersensibilidade $(\mathrm{PH})$, doenças pulmonares intersticiais (DPI), beriliose crônica, presença de células malignas e exposição ao amianto (PATEL; BHIMJI, 2017). Entre os principais aspectos estão:

- Por não haver uma padronização de valores específicos com boa evidência, a análise é realizada por comparação dos valores de corte da quantificação celular, como descrito abaixo (PATEL; BHIMJI, 2017):

- Neutrófilos aumentados (> 5\%): sugerem fibrose pulmonar idiopática (FPI), síndrome do desconforto respiratório agudo (SDRA), infecção e distúrbios do tecido conjuntivo (PATEL; BHIMJI, 2017).

- Eosinofilia $>25 \%$ : sugerem doenças pulmonares eosinofílicas como pneumonia eosinofílica aguda, pneumonia eosinofílica crônica e síndrome de Churg-Strauss (PATEL; BHIMJI, 2017);

- Linfocitose $>50 \%$ : sugerem pneumonite por hipersensibilidade. Quando há $15 \%$ ou mais de linfócitos, as razões cluster of differentiation (CD)4 / CD8 podem ser avaliadas (PATEL; BHIMJI, 2017).

- CD4 / CD8 elevado: sugere pneumonite por hipersensibilidade (crônica ou tabagismo), sarcoidose, beriliose, asbestose, doença de Crohn, distúrbios do tecido conjuntivo (PATEL; BHIMJI, 2017);

- CD4 / CD8 normal: sugere tuberculose e/ou malignidades (PATEL; BHIMJI, 2017);

- CD4 / CD8 baixo: sugere pneumonite de hipersensibilidade aguda, silicose, doença pulmonar induzida por drogas, infecção por imunodeficiência humana e bronquiolite obliterante com pneumonia organizada (PATEL; BHIMJI, 2017);

- Coletas progressivas de fluidos escurecidos com aspecto sanguinolento são altamente sugestivas de hemorragia alveolar difusa. Macrófagos carregados de hemossiderina também podem ser evidentes na análise de LBA (PATEL; BHIMJI, 2017).

Os riscos para a realização do LBA são extremamente baixos, com hipoxemia sendo a mais comum. Febres baixas nas primeiras vinte e quatro horas após os procedimentos podem ocorrer em até um terço de pacientes, isso devido à atividade de citocinas e não representam infecção real. Alterações radiográficas também são esperadas por causa de solução salina parcialmente retida (MILLER et al., 2018).

Em pacientes críticos submetidos a ventilação mecânica, após a realização do LBA, a taxa de hipo-oxigenação (saturação periférica arterial de oxigênio da hemoglobina $(\mathrm{SatO} 2) \leq 88 \%$ ) e/ou broncoespasmo pode chegar a $9 \%$ dos casos, 
porém, esse evento pode ser administrável para garantir a continuidade do procedimento. Após 1 hora do término do procedimento, pode-se observar uma diminuição na relação média de pressão arterial de oxigênio $\left(\mathrm{PaO}_{2}\right) /$ fração inspirada de oxigênio $\left(\mathrm{FiO}_{2}\right)$, que deve se recuperar totalmente para a linha de base após 24 horas, sem necessidade do aumento da pressão expiratória final positiva no ventilador mecânico ou dos níveis de $\mathrm{FiO}_{2}$ (SCHNABEL et al., 2015).

Para se minimizar os riscos da realização do LBA, recomenda-se que um broncoscopista experiente realize o procedimento enquanto outro médico examina o paciente, regula a analgesia e ajusta o apoio de funções vitais, conforme necessário. Visto os riscos, os benefícios do procedimento devem ser analisados e comparados com medidas de diagnóstico menos invasivas. Quando nenhuma causa infecciosa é detectada, se faz necessária uma busca de diagnósticos alternativos, assim, essa prática poderia afetar beneficamente o resultado dos pacientes e, ao mesmo tempo, reduz o uso de antibiótico desnecessário. O controle racional de antibióticos torna-se cada vez mais importante com a rápida emergência e disseminação de microrganismos resistentes a múltiplas drogas particularmente no ambiente de terapia intensiva (SCHNABEL et al., 2015).

Abaixo, um breve resumo das principais doenças que foram investigadas através do LBA no presente estudo.

1.1.1 LBA e as doenças pulmonares intersticiais (DPIs)

As DPIs são um grupo amplo de doenças pulmonares que acometem o interstício do pulmão devido processo inflamatório e de fibrose de forma aguda e crônica, onde cada doença apresenta fisiopatologia própria. Em comum, esse grupo de doenças apresenta alterações radiológicas, histológicas e clínicas semelhantes, o que dificulta o diagnóstico etiológico e o tratamento (PRASAD et al., 2017).

Dentre os recursos utilizados para o diagnóstico das doenças intersticiais, o LBA é frequentemente empregado para guiar o tratamento. A segurança do resultado do exame de LBA depende de sua realização correta desde a coleta até a análise. A coleta do LBA deve ser realizada na região pulmonar guiada previamente por tomografia computadorizada de alta resolução e o material que retorna na coleta é melhor aproveitado para o diagnóstico de DIP quando supera $30 \%$ da quantidade instilada, para representar melhor o espaço alveolar (MEYER et al., 2012). 
Dentre as características clínicas da DIP podemos descrever a dispneia ao esforço, infiltrados pulmonares bilaterais na imagem torácica e alterações na gasometria. Do ponto de vista patológico, podemos citar um acúmulo de células inflamatórias e imunológicas que costumam ser acompanhadas por matriz extracelular anormal nas vias aéreas distais, paredes alveolares e interstício. A sua evolução decorre por meses ou anos, podendo ter suas causas conhecidas ou desconhecidas (MEYER et al., 2012).

Entre as DPIs com causas conhecidas, estão as pneumoconioses, as causadas por doenças do tecido conjuntivo e a pneumonite por hipersensibilidade (PH). Entre as DPIs de causa desconhecida estão a sarcoidose e as pneumonias intersticiais idiopáticas, que englobam fibrose pulmonar idiopática, pneumonia intersticial não específica, pneumonia intersticial descamativa, bronquiolite respiratória com doença pulmonar intersticial, pneumonia intersticial aguda, pneumonia intersticial criptogênica em organização e pneumonia linfoide (MEYER et al., 2012).

De forma geral, a DPI se manifesta e evolui de forma crônica, porém, algumas variantes podem ter uma apresentação aguda ou ser agudizada, como exemplo de manifestações agudas podemos citar pneumonia intersticial aguda, pneumonia eosinofílica aguda, pneumonite de hipersensibilidade aguda, hemorragia alveolar difusa, pneumonia intersticial criptogênica em organização, reações medicamentosas e exacerbações agudas de fibrose pulmonar idiopática (MEYER et al., 2012).

Nos casos de suspeita de DIP, após investigação na avaliação inicial dos aspectos clínicos e da imagem torácica dos pacientes, o LBA pode ser utilizado para o diagnóstico principalmente quando não é possível se assegurar de um padrão confiável de pneumonia interstitial usual (PIU) na imagem pulmonar. Nesse processo de diagnóstico, o LBA que apresentar-se predominantemente inflamatório (aumento de linfócitos, eosinófilos ou neutrófilos) pode sugerir DIP, sendo que um perfil celular normal não exclui a possiblidade de anormalidades microscópicas no tecido pulmonar. Esse conjunto de informações, fornecem dados úteis para o diagnóstico de pacientes em investigação de DIP (MEYER et al., 2012).

\subsubsection{LBA e as infecções pulmonares}

Quadros infecciosos pulmonares são frequentes em variados grupos de pacientes, apresentando-se principalmente como complicações causadas por 
diferentes patógenos. Essa heterogeneidade dificulta o diagnóstico e manejo clínico do quadro.

A pneumonia é um tipo de infecção respiratória inferior aguda comum e, potencialmente, grave. $O$ resultado dessa infecção é determinado pelo grau em que 0 sistema imunológico é eficaz para promover a proteção do indivíduo e a inflamação que pode deteriorar o organismo (QUINTON; WALKEY; MIZGERD, 2017).

A pneumonia deve percebida além da infecção aguda do pulmão, em uma situação que se soma ao quadro resultante de suscetibilidade inerente às condições crônicas com consequências graves ao organismo (QUINTON; WALKEY; MIZGERD, 2017).

As exposições aos micróbios que causam a pneumonia são rotineiras, inevitáveis e a seleção de indivíduos que desenvolverão pneumonia após essa exposição é consequência de condições inerentes ao próprio organismo. A pesquisa microbiana se torna útil para esse combate, resultando em melhores medicamentos, mas isso pode não ser o suficiente, os micróbios responsáveis são muito numerosos, onipresentes e variados (QUINTON; WALKEY; MIZGERD, 2017).

O LBA é comumente utilizado para investigar quadros pulmonares através de amostras microbiológicas e citológicas com o objetivo de diagnosticar e guiar a terapêutica desses pacientes (RAND et al., 2013).

Em pacientes imunocomprometidos, o LBA mantém um papel importante no estabelecimento do diagnóstico microbiológico, sendo esse diagnóstico possível em $60,8 \%$, podendo o seu rendimento variar de acordo com a causa da imunossupressão (CHOO et al., 2019).

\subsubsection{LBA, a tuberculose e as micobacterioses}

A tuberculose (TB) é uma doença antiga e que já foi intratável. O seu tratamento de maneira eficaz com medicamentos, foi possível pela primeira vez na década de 1940, e em combinação com aspectos sociais e econômicos desenvolvidos, permitiram algumas partes do mundo reduzir o problema da tuberculose para níveis mais baixos com o passar do tempo. Na maioria dos países, no entanto, o fim dos casos de tuberculose é um grande desafio de saúde pública. Diagnóstico e tratamento de pessoas com tuberculose evita milhões de mortes a cada ano (cerca de 54 milhões durante o período de 2000 - 2017), mas há dificuldades persistentes na detecção e 
tratamento. Apesar dos dados de resultados de tratamento mais recentes para novos casos mostrarem uma taxa global de sucesso do tratamento de 82\% (em 2016), em todo o mundo, em 2017, 6,4 milhões de novos casos de TB foram notificados oficialmente às autoridades (ORGANIZAÇÃO MUNDIAL DA SAÚDE, 2018).

A instalação da TB tem início via pulmonar e é causada pelo Mycobacterium tuberculosis (Mtb). Nos pulmões, se cria uma infecção na sua periferia após o agente ser depositado pela inalação. Os primeiros momentos resultam em poucos ou nenhum sintoma, sendo que a tuberculose se desenvolve lentamente. Os indivíduos com tuberculose primária têm muito mais probabilidade de ser assintomáticos ou minimamente sintomáticos. O sintoma constitucional mais frequentemente observado é febre moderada no início, mas que se torna bastante acentuada à medida que a doença evolui, geralmente presente no final da tarde com sudorese noturna. Outros sintomas presentes são mal-estar, irritabilidade, fraqueza, fadiga incomum, dor de cabeça, perda de peso, tosse associada ou não à expectoração frequentemente associada a hemoptise leve conforme a doença se desenvolve, dor torácica localizada ou pleurítica e falta de ar, que podem ocorrer com o agravamento da doença (LYON; ROSSMAN, 2017).

Os exames laboratoriais de rotina raramente são úteis para estabelecer ou sugerir o diagnóstico de TB, enquanto a radiografia de tórax é o estudo individual mais útil para sugerir o diagnóstico de tuberculose, caracterizando de forma específica a tuberculose primária e a tuberculose de reativação (LYON; ROSSMAN, 2017).

O escarro é a melhor amostra para se diagnosticar o agente Mtb, e o escarro induzido pode ser uma alternativa para pacientes que não produzem escarro. Esfregaços do conteúdo gástrico para pesquisa de bacilos álcool-ácido resistentes podem apresentar limitações para o diagnóstico. Para o diagnóstico, pode ser necessário recorrer à broncoscopia em alguns casos (LYON; ROSSMAN, 2017).

Procedimentos indiretos, como os ensaios de liberação de interferon-gama, são o padrão moderno para o diagnóstico de infecção tuberculosa latente em adultos. Esses ensaios detectam a secreção de interferon-gama por linfócitos $T$, que são estimulados por meio de antígenos relativamente específicos de TB. O teste de liberação de interferon-gama não é adequado para todos os diagnósticos de TB, isso porque não distingue a TB latente e a doença ativa (SUÁREZ et al, 2019).

Os recursos para o diagnóstico de TB contam principalmente com a visualização microscópica direta do patógeno, cultura e testes de amplificação de 
ácido nucleico. A amostra pode ser baseada na coleta de escarro, porém, nesse caso precisa-se obter amostras em três dias diferentes. A microscopia de amostras de escarro, secreção brônquica ou fluido do LBA é econômica, rápida e representa um marcador de infecção do paciente (SUÁREZ et al, 2019).

A especificidade da microscopia também é limitada, porque não consegue distinguir Mtb de micobactérias não tuberculosas. São necessários vários dias ou várias semanas de cultura para um resultado positivo. A cultura mostra-se como padrão ouro do diagnóstico de TB (SUÁREZ et al, 2019).

O LBA obtido pela broncoscopia tem maior sensibilidade do que o escarro para a detecção de Mtb, porém, a broncoscopia é invasiva e mais cara, e pode não ser adequada para todos os pacientes (LIU et al., 2018).

Um estudo recente, mostrou que o LBA é mais eficaz que o escarro para detecção de Mtb por cultura e amplificação de ácido nucleico. O LBA deve ser realizado principalmente para casos suspeitos de TB pulmonares quando o escarro ou esfregaço apresentam culturas negativas (AHMAD et al., 2019).

Com as melhorias das condições sociais e econômicas, atualmente, há uma tendência de aumento da incidência de infecções pulmonares por micobactérias não tuberculosas e tendência de diminuição de TB, principalmente em países desenvolvidos. As micobactérias não tuberculosas são patógenos ambientais, sendo assim, as exposições são responsáveis por promover as interações entre o patógeno e o hospedeiro (CHIN et al., 2020).

O termo "micobactérias não tuberculosas" é utilizado para se referir a Mycobacterium que não faz parte do complexo $M$. tuberculosis e também exclui $M$. leprae. São organismos encontrados no meio ambiente em todo o mundo e, devido à sua espessa parede celular rica em lipídios, são resistentes ao calor, $\mathrm{pH}$, a muitos desinfetantes, antibióticos e acometem seres humanos há mais de 70 anos (COWMAN et al., 2019).

As micobactérias não tuberculosas constituem um amplo grupo, porém, poucas são capazes de causar doenças em humanos; elas constituem subgrupo de crescimento rápido, onde estão $M$. abscessus, $M$. chelonae e o $M$. fortuitum, e um subgrupo de crescimento lento, onde estão o M. avium (MAC), M. xenopi, M. kansasii, M. simiae, M. malmoense e M. szulgai. O seu diagnóstico depende da integração de resultados clínicos, radiológicos e microbiológicos (COWMAN et al., 2019). 
Devido à gravidade de alguns casos, geralmente são necessárias associações de antibióticos por períodos prolongados e, ainda, a cirurgia pode ser benéfica em algumas situações (COWMAN et al., 2019).

Assim, a análise dos componentes do fluido do LBA pode auxiliar na deteç̧ão de pacientes infectados por doença pulmonar por Mycobacterium, incluindo Mtb e MAC (INOMATA et al., 2018).

\subsubsection{LBA e as infecções fúngicas}

A infecção fúngica é um dos acometimentos pulmonares infecciosos que podem cursar com distúrbios graves e difícil controle clínico e, em pacientes com comprometimento imunológico, torna o caso ainda mais grave. Entre os fungos mais encontrados estão o Aspergillus, Cryptococcus, Pneumocystis e micoses endêmicas que podem causar risco à vida (LI; LU; MENG, 2019).

O fungo Aspergillus é uma das espécies de fungos. Eles podem liberar conídios que são transportados pelo ar e são pequenos a ponto de alcançar as vias aéreas humanas e alvéolos pulmonares, podendo dar início à sequência infecciosa nos casos de falha da ativação dos macrófagos alveolares (LI; LU; MENG, 2019; YAGUCHI, 2011).

O Cryptococcus, quando atinge os pulmões após a sua inalação, pode causar a criptococose. O resultado mais grave da infecção por Cryptococcus é a meningite criptocócica (LI; LU; MENG, 2019).

A pneumonia por Pneumocystis, desencadeada pelo fungo Pneumocystis, é mais comumente encontrada em pacientes imunocomprometidos com ou sem a síndrome da imunodeficiência adquirida (LI; LU; MENG, 2019).

As micoses endêmicas são variáveis de acordo com características locais. $\mathrm{Na}$ América do Norte, as principais micoses endêmicas são a coccidioidomicose, a histoplasmose e a blastomicose, já a paracoccidioidomicose se apresenta principalmente na América Latina, sendo o Brasil responsável por grande parte dos casos. Os sintomas podem variar de acordo com a resposta imunológica individual (LI; LU; MENG, 2019).

Os fungos potencialmente causadores de distúrbios graves formam um grande e variado grupo, com alguns dos seus componentes citados aqui. O LBA se faz útil 
para identificar e guiar tratamentos desses agentes e otimizar as terapêuticas (SMITH; KAUFFMAN, 2012).

\subsubsection{LBA e a pneumonite de hipersensibilidade}

A pneumonite de hipersensibilidade (PH), também conhecida como alveolite alérgica extrínseca, é caracterizada por inflamação do parênquima, alvéolos e vias aéreas terminais dos pulmões, que se dá início por antígenos que são inalados por uma pessoa suscetível. Como agentes etiológicos podemos encontrar compostos orgânicos de alto peso molecular (como bactérias, fungos, amebas, proteínas vegetais e animais) ou haptenos inorgânicos de baixo peso molecular (como isocianatos) e drogas (incluindo amiodarona, nitrofurantoína e minociclina) (WHATTS; GRAMMER , 2019).

Os sintomas de $\mathrm{PH}$ podem se apresentar poucas horas após a exposição ao agente causador, ou seja, de maneira aguda, e incluem mal-estar, febre, tosse e dispneia. A gravidade dos sintomas geralmente atinge o pico em torno de 18 a 24 horas após a exposição e tem sua resolução após a se interromper a exposição ao agente causador. Assim, esses casos, raramente, são submetidos à biópsia (MILLER, 2018).

A PH quando causada por exposição crônica e menos intensa, apresenta sintomas mais discretos e pode ser progressiva e, quando sem tratamento adequado, pode causar insuficiência respiratória fulminante e morte por fibrose em estágio avançado (MILLER, 2018).

Há vários critérios para diagnósticos de $\mathrm{PH}$, assim, é proposta uma investigação abrangente baseada na análise da exposição conhecida a um agente agressor, achados clínicos, radiográficos ou fisiológicos, LBA com linfocitose e achados histopatológicos compatíveis (MILLER, 2018).

Em relação às imagens, a tomografia computadorizada de alta resolução pode fornecer informações diagnósticas úteis, os achados são variáveis e dependem do estágio da doença. Os achados característicos incluem vidro fosco centrolobular ou opacidades nodulares com evidência de aprisionamento de ar na porção média a superior dos lobos pulmonares, que são mais característicos dos casos subagudos, que também podem apresentar alterações fibróticas (MILLER, 2018). 
Já os achados patológicos, por sua vez, estão predominantemente nas vias aéreas, quando de maneira subaguda apresentam pneumonia intersticial peribronquiolar, bronquiolite crônica e células gigantes peribronquiolares com ou sem granulomas malformados, e alguns casos podem ter células gigantes multinucleadas ou granuloma em espaços aéreos. Nos casos de PH com fibrose, a fibrose torna-se cada vez mais pronunciada, com padrão subpleural irregular com distorção arquitetônica, geralmente com focos fibroblásticos, pneumonia intersticial fibrótica, inespecífica e padrão fibrótico irregular peribrônquico acentuado. Fibrose peribronquiolar, fibrose em ponte entre áreas peribronquiolares adjacentes, metaplasia peribronquiolar e cicatriz subpleural também são frequentes. $\mathrm{Na}$ fibrose grave, está presente apenas a fibrose em favo de mel (estágio terminal) (MILLER, 2018).

A análise do LBA pode fornecer dados úteis para o diagnóstico de $\mathrm{PH}$ que se apresenta com linfocitose e quando em análise mais específica, linfocitose com baixa proporção de CD4:CD8. Porém, a linfocitose pode ser observada em várias condições, como sarcoidose, doenças do tecido conjuntivo, efeito de drogas, pneumonite associada a síndrome da imunodeficiência humana adquirida, etc., portanto, não é específica para PH (MILLER, 2018).

\subsubsection{LBA e as doenças ocupacionais}

Cada indivíduo esta susceptível as condições de trabalho inerentes a sua profissão. As exposições ocupacionais interferem no estado de saúde do trabalhador, podendo muitas ter impacto respiratório devido à inalação de substâncias específicas, vapores, gases, poeiras ou fumaças (BLANC et al., 2019).

As doenças pulmonares causadas pela inalação de poeira e fibras, sendo orgânicas ou não, são conhecidas como pneumoconiose, sendo os tipos mais encontrados a asbestose, causada pelo amianto, a silicose, causada pela sílica, e o pulmão de minerador, causada pela inalação de carvão (DELIGHT; SACHS, 2021; RIVERA-ORTEGA; MOLINA-MOLINA, 2019).

A pneumoconiose começa com uma resposta inflamatória e pode evoluir para nódulos e fibrose maciça. Não há cura para a pneumoconiose e o prognóstico é ruim na fase fibrótica e, ainda, no caso da silicose pode levar ao carcinoma. A pneumoconiose pode apresentar-se ou não com enfisema, ou ainda, em alguns 
casos, ser sobreposta à doença pulmonar obstrutiva crônica (DPOC) (DELIGHT; SACHS, 2021).

Estudos sugerem que a análise do líquido do LBA através da microscopia eletrônica, é capaz de auxiliar o diagnóstico de doenças ocupacionais usando-se da detecção de fibras de amianto e partículas de ferro entre outros fragmentos, de maneira menos invasiva e mais segura do que a biópsia cirúrgica, sendo assim útil para a avaliação da exposição ocupacional (KIDO et al., 2017).

\subsubsection{LBA e a sarcoidose}

A sarcoidose é uma doença granulomatosa sistêmica, sem etiologia esclarecida, com potencial para afetar qualquer órgão, porém, é mais frequente nos pulmões e nos linfonodos intratorácicos. Os indivíduos acometidos geralmente apresentam tosse sem causa aparente, são adultos jovens ou de meia-idade, apresentam falta de ar ou sintomas constitucionais, especialmente entre negros ou escandinavos (SOTO-GOMEZ; PETERS; NAMBIAR, 2016).

O diagnóstico depende da apresentação clínica e radiológica compatível, evidência patológica de granulomas não caseosos e da exclusão de outras doenças com achados semelhantes, como infecções ou malignidade. O diagnóstico precoce e preciso da sarcoidose continua desafiador, isso porque as apresentações iniciais podem variar, muitos pacientes são assintomáticos e não há um único teste diagnóstico confiável. A sarcoidose é mais comum entre adultos de 20 a 50 anos (mais de $80 \%$ dos casos), com um segundo pico de incidência entre 50 e 65 anos principalmente entre as mulheres na Escandinávia e no Japão (SOTO-GOMEZ; PETERS; NAMBIAR, 2016).

A sarcoidose se estabelece como granuloma não caseoso devido à inflamação em curso que causa o acúmulo de células $T$ ativadas e macrófagos, que secretam citocinas e fator de necrose tumoral-a. Estudos sugerem que é o resultado de uma resposta imune exagerada em um indivíduo geneticamente suscetível a um antígeno indefinido, como certos fatores ambientais, micróbios, ou antígenos parcialmente degradados que dá início à sua instalação (SOTO-GOMEZ; PETERS; NAMBIAR, 2016).

Outro ponto fundamental sobre a sarcoidose pulmonar é o seu estadiamento. Um trabalho recente observou que a radiografia de tórax ainda é valiosa para o 
prognóstico da sarcoidose pulmonar, pois, foram encontradas correlações significativas entre os estágios radiológicos da sarcoidose e os parâmetros da função pulmonar, porém, a tomografia computadorizada de alta resolução de tórax foi significativamente superior à radiografia de tórax na detecção de alterações mediastinais e do parênquima pulmonar (ALEKSONIENÈ et al., 2021).

A análise do LBA tem sido usada para o diagnóstico de sarcoidose, sendo a linfocitose e as relações CD4/CD8 alteradas associadas ao seu diagnóstico (AKYIL et al., 2020).

Em uma pesquisa sobre sarcoidose, a porcentagem de neutrófilos encontrada no LBA aumentou nos estágios mais avançados da doença; o aumento na porcentagem de linfócitos LBA foi associado ao padrão de restrição na função pulmonar, e o valor diagnóstico de LBA para sarcoidose foi maior quando foram encontrados os padrões radiológicos típicos da doença em estágios mais iniciais, e ainda o tabagismo também foi capaz de interferir, diminuindo o valor diagnóstico da razão CD4/CD8, mostrando assim a relação do LBA e a sarcoidose pulmonar (ALEKSONIENÈ et al., 2017).

\subsubsection{LBA e a fibrose pulmonar}

A fibrose pulmonar idiopática (FPI) é um acometimento pulmonar intersticial que se apresenta de forma progressiva, com causa desconhecida, afetando desproporcionalmente idosos, e é definida pelo padrão histopatológico de PIU que é caracterizada por distribuição irregular de áreas de fibrose com faveolamento periférico e focos fibroblásticos dispersos resultantes de centros microscópicos de lesões agudas (LEE et al.,2018).

A FPI tem como característica a deposição progressiva de tecido fibrótico nos pulmões, evoluindo de maneira geral com mau prognóstico. A necessidade de um diagnóstico precoce, não invasivo, confiável e uma estratificação de doença mais precisa são os seus desafios (SGALLA et al., 2018).

A FPI possui uma patogênese complexa e indefinida. Várias exposições ambientais e microbianas têm sido propostas, porém, fatores genéticos e epigenéticos individuais continuam sendo os mais importantes para o desenvolvimento do processo fibrótico. Assim, a suscetibilidade genética e a microlesão repetida do epitélio alveolar foi reconhecida como a primeira causa de um processo de reparo alterado, em que as 
células pulmonares desenvolvem comportamentos aberrantes e causam 0 desenvolvimento e sustentação do processo fibrótico. As exposições ambientais também estão associadas a esse processo, em que achados como tabagismo, exposição ao pó de metal, produtos da agricultura e pecuária, pó de madeira e pedra, areia e sílica mostram-se como risco para desenvolvimento de FPI. Um desequilíbrio na composição da comunidade bacteriana do indivíduo pode ser observado em pacientes com doença pulmonar intersticial, quando comparados com pulmões saudáveis (SGALLA et al., 2018).

Com o desenvolver da FPI, algumas alterações são notadas. Os principais sintomas apresentados são a tosse não produtiva e dispneia progressiva aos esforços, além de contar com achados físicos cruciais como hipertrofia do músculo escaleno, crepitações finas bibasilares e baqueteamento digital (KISHABA, 2019).

O LBA pode ser empregado no auxílio ao diagnóstico da fibrose pulmonar em casos duvidosos, sendo a contagem de linfócitos no LBA significativamente correlacionada ao estágio de fibrose pulmonar apresentado na tomografia computadorizada (TC) de tórax, bem como com a capacidade pulmonar total e capacidade vital (SZTURMOWICZ et al., 2020).

\subsubsection{LBA e as neoplasias pulmonares}

O câncer de pulmão está entre os mais diagnosticados e entre as principais causas de morte no mundo, tendo o tabagismo como o seu maior fator de risco (SCHABATH; COTE, 2019).

A maioria dos pacientes com câncer de pulmão tem seu diagnóstico já no estágio avançado, e as perspectivas de cura são limitadas, sendo o diagnóstico inicial associado a sobrevida global substancialmente maior (SCHABATH; COTE, 2019).

Em relação aos diagnósticos, o líquido do LBA obtido durante a broncoscopia, por refletir o microambiente do sistema respiratório e representar o líquido da superfície alveolar com seus vários componentes celulares, pode ser utilizado como uma das opções. As células inflamatórias obtidas do LBA podem ser usadas para avaliar diversas situações (ZHANG et al.; 2020).

O LBA se mostra viável para colaborar com o diagnóstico de neoplasias pulmonares periféricas devido ao fato da lavagem realizada para coleta do material 
atingir a periferia pulmonar e ser capaz de obter células tumorais destacadas das lesões pulmonares (ZHONG et al.; 2018).

Por outro lado, o diagnóstico de lesões neoplásicas do pulmão pelo LBA também pode ser um problema, sendo que algumas condições de lesões malignas podem falsear outras doenças a ponto de confundir diagnósticos (RADHA; AFROZ; PRASAD; RAVINDRA, 2014).

\subsection{Gastos em saúde}

A constituição de 1988 estabeleceu que todo cidadão brasileiro tem direito ao acesso à saúde de maneira integral. Desde então, políticas públicas são desenvolvidas para cobrir as necessidades da população e, por outro lado, tentar adequar o orçamento às nossas realidades. Com a implantação do sistema, o número de beneficiados passou de 30 milhões de pessoas para 190 milhões (GOVERNO DO BRASIL, 2018).

Atualmente, 80\% da população depende exclusivamente do Sistema Único de Saúde (SUS) para ter acesso aos serviços de saúde. A implantação do SUS unificou - sistema, já que antes a saúde era responsabilidade de vários ministérios, e descentralizou sua gestão. A saúde deixou de ser exclusiva do Poder Executivo Federal e passou a ser administrada por Estados e municípios. Segundo o Ministério da Saúde, o SUS tem 6,1 mil hospitais credenciados, 45 mil unidades de atenção primária e 30,3 mil Equipes de Saúde da Família. O sistema realiza 2,8 bilhões de procedimentos ambulatoriais anuais, 19 mil transplantes, 236 mil cirurgias cardíacas, 9,7 milhões de procedimentos de quimioterapia e radioterapia e 11 milhões de internações (MINISTÉRIO DA SAÚDE, 2018).

Na saúde pública, a atenção especializada envolve alta tecnologia e alto custo. Um dos objetivos do SUS é manter o acesso aos serviços especializados e qualificados, integrando níveis de atenção à saúde (atenção básica e de média complexidade). Procedimentos da alta complexidade realizados na rede de saúde, em sua maioria, apresentam impacto financeiro extremamente alto (MINISTÉRIO DA SAÚDE, 2018).

A segunda década do século XXI tem como característica a preocupação com a sustentabilidade de sistemas de saúde, isso porque a capacidade de se manter serviços ofertados em saúde é fundamental para sua qualidade. Além dessa 
necessidade de manter serviços na área da saúde para se manter a qualidade, é válido ressaltar que nenhum país dispõe de recursos que permitam financiar intervenções terapêuticas ou diagnósticas que resultem em benefícios de magnitude pequena, ou nula (DIRETRIZ DE AVALIAÇÃO ECONÔMICA, 2014).

As avaliações econômicas em saúde são definidas como técnicas analíticas formais para comparar diferentes alternativas de ação propostas, levando em consideração custos e consequências para a saúde, positiva e negativamente. Essas análises comparativas ponderam os custos dos recursos aplicados e das consequências obtidas em termos de saúde, ajudando nas decisões sobre a priorização de intervenções e a alocação de recursos (DIRETRIZ DE AVALIAÇÃO ECONÔMICA, 2014).

Assim, otimizar o uso dos recursos em saúde se faz necessário e se apresenta como alternativa para se manter o sistema viável, disponível e eficaz à população. 
2 OBJETIVOS 
Os objetivos do presente estudo foram:

a) Avaliar o impacto do exame de LBA no tratamento de pacientes do Hospital das Clínicas da Faculdade de Medicina de Ribeirão Preto - USP (HCFMRP);

b) Identificar indicações que promovam melhor aproveitamento do LBA, viabilizando o seu uso;

c) Proporcionar melhor aproveitamento do serviço de saúde e seus recursos. 
O LBA é o material colhido do compartimento alveolar do pulmão por meio da instilação e aspiração de líquido (soro fisiológico) realizadas por broncoscopia flexível, seguida da análise citológica e microbiológica para auxiliar no diagnóstico de doenças pulmonares. A broncoscopia, em geral, é indicada por outras razões além do LBA, como, por exemplo, para biópsia pulmonar. O LBA é uma etapa que aumenta o tempo de broncoscopia e tem custos para seu processamento e análise, por isso, precisa ser justificado.

Este estudo foi desenvolvido para se conhecer o impacto do exame de LBA no tratamento de 1000 pacientes do HCRP, se estabelecer a viabilidade do LBA para direcionar suas indicações e proporcionar melhor aproveitamento do serviço de saúde e seus recursos pela análise de subgrupos de pacientes com hipóteses diagnósticas que proporcionem o melhor aproveitamento dos recursos investidos no procedimento. 
4 MATERIAIS E MÉTODOS 


\subsection{Desenho do estudo}

Trata-se de uma análise do uso e da viabilidade do LBA em um serviço de saúde especializado, feita através de avaliação retrospectiva de 1000 exames realizados, visando o seu impacto no tratamento de cada paciente.

O estudo teve início pelos levantamentos dos exames de LBA já coletados no Serviço de Pneumologia do Hospital das Clínicas da Faculdade de Medicina de Ribeirão Preto - USP (HCFMRP). Esse levantamento incluiu o seguimento clínicoterapêutico dos pacientes pesquisados, para avaliarmos a capacidade desse exame em guiar o tratamento de cada caso. Isso se deu por meio de revisão de arquivo médico dos casos de LBA realizados entre os anos de 2006 e 2018, ano em que se iniciou esta pesquisa (2018), completando o total de 1000 casos.

Foi realizada a caracterização da amostra e triagem das hipóteses diagnósticas que motivaram as indicações para o exame de LBA, e de seus respectivos desfechos clínicos, para assim, se estabelecer os casos que mais se beneficiam da realização do LBA.

\subsection{Casuística}

Foram selecionados pacientes que realizaram o exame de LBA na Seção de Pneumologia do HCFMRP, no âmbito hospitalar e ambulatorial, na unidade Campus, seguido de análise dos respectivos prontuários médicos.

\subsection{Coleta e processamento do LBA}

Por tratar-se de um estudo retrospectivo, o presente trabalho contou com as análises já realizadas pela Seção de Pneumologia do HCFMRP, onde seus métodos são padronizados para a rotina do serviço, como descrito por Faccio (2004) e apresentadas abaixo:

O LBA destinou-se à obtenção de material para ser submetido ao estudo citológico no laboratório da Seção de Pneumologia do HCFMRP, segundo técnicas padronizadas. Para o procedimento foi utilizado broncofibroscópio flexível. A técnica consistiu na passagem do broncofibroscópio, após anestesia das vias aéreas superiores, até o encunhamento do aparelho em um brônquio distal, geralmente de $3^{\text {a }}$ ou $4^{a}$ geração. Após, a solução salina estéril foi infundida em alíquotas de $20 \mathrm{ml}$, através do canal do aparelho, sendo que cada uma das alíquotas foi aspirada e 
coletada em um único frasco que foi encaminhado rapidamente para o processamento e análise. O material se manteve devidamente identificado e em condições assépticas.

A análise do material também seguiu técnica padronizada, onde todo o material foi filtrado em uma folha de gaze fina para a eliminação do muco e colocado em tubos plásticos de 15 ou $50 \mathrm{ml}$ medindo seu volume e observando suas características. Então, o material foi centrifugado por 10 minutos com 2.000 rotações por minuto (RPM) para se separar o sobrenadante e armazena-lo em tubos plásticos para congelamento. Foi ainda adicionado soro fisiológico até o material apresentar um volume final de $2 \mathrm{ml}$. Foi então misturado usando-se a pipeta e preparado para a contagem em câmara de Neubauer (FACCIO, 2004).

O material foi preparado para essa contagem celular total pelo acréscimo de $200 \mu \mathrm{L}$ de líquido de Turk ou solução de violeta cristal a $10 \mu \mathrm{L}$ da solução de células do LBA. Foram retirados $10 \mu \mathrm{L}$ que foram colocados na câmara de Neubauer. Foram contadas 600 células no microscópio óptico, para se determinar o número relativo a cada um dos tipos celulares e também a análise qualitativa, onde era observada a presença ou não de outros tipos celulares. Foi então realizada a pesquisa de microorganismos como M. tuberculosis, fungos, P. carinii, etc., com lâminas coradas por métodos específicos (FACCIO, 2004).

A contagem diferencial das células foi realizada por um esfregaço com a solução das células do LBA que foi deixada para secar em lâmina por 20 minutos, empregando-se as seguintes colorações:

- Coloração de May-Grünwald-Giemsa: A solução de May-Grünwald foi colocada na lâmina por 3 minutos, lavada rapidamente com água destilada e trocada pela solução de Giemsa - 1:10 ou 1:20 (diluída em água destilada), em seguida, lavada novamente em água destilada, deixada secar e, finalmente, foi realizada a limpeza do fundo da lâmina com gaze e álcool (FACCIO, 2004).

- Coloração pela Toluidina (Pneumocystis carinii): A solução de Toluidina foi preparada com $0,15 \mathrm{~g}$ de pó de Toluidina, $30 \mathrm{ml}$ de água destilada, $1 \mathrm{ml}$ de $\mathrm{HCL}$, $60 \mathrm{ml}$ de etanol (100\%) e colocada em vidro ao abrigo da luz. A lâmina foi secada por 30 minutos, colocada por 10 minutos (sendo misturada periodicamente) em uma solução de $30 \mathrm{ml}$ de ácido acético e $10 \mathrm{ml}$ de ácido sulfúrico. Após, foi lavada em água corrente por 5 minutos e passada por 10 segundos no álcool (95\%), em seguida foi deixada por 10 segundos no álcool (100\%) e colocada para secar (FACCIO, 2004). 
- Coloração de Ziehl-Neelsen: A fucsina foi colocada em toda a lâmina e deixada por 10 minutos, submetida a aquecimento de duas a três vezes, após foi lavada com água destilada e deixada em álcool-ácido por alguns segundos, e, lavada novamente com água destilada. A lâmina foi também submetida a azul de metileno por 30 segundos, lavada uma última vez e deixada para secar (FACCIO, 2004).

As análises do material do LBA foram complementadas pelas técnicas:

- TB - Teste rápido molecular: Para permitir a detecção automatizada simultânea do Mtb e a resistência à rifampicina em amostras biológicas, através da técnica de reação em cadeia de polimerase (PCR) em tempo real e semiquantitativo. Para o procedimento, foi utilizado o equipamento GneXpert Dx com cartuchos descartáveis com os reagentes de PCR, que automatizou o processamento das amostras e amplificou os ácidos nucléicos e a detecção das sequências, utilizando ensaios de PCR e RT - PCR (transcriptase reversa - PCR) em tempo real. Para isso, foi utilizada uma amostra de $1,0 \mathrm{ml}$ de sedimento completada até $2,2 \mathrm{ml}$ com reagente de amostra (tampão). Em seguida, foi adicionado o reagente ao material e homogeneizado. Então, o preparado foi pipetado e transportado para o compartimento do cartucho para a análise do seu conteúdo. (HOSPITAL DAS CLÍNICAS DA FACULDADE DE MEDICINA DE RIBEIRÃO PRETO, 2021).

- Baciloscopia: É um exame básico para o diagnóstico bacteriológico da tuberculose. A técnica consistiu na visualização de BAAR através da coloração de Ziehl Neelsen, sendo esse teste baseado na capacidade das micobactérias em reter a fucsina após a coloração e manutenção após ação do álcool - ácido, devido à presença de lipídios em sua parede celular, entre eles o ácido micólico. Para a análise, foi utilizado o volume de 5 a $10 \mathrm{ml}$ de amostra, sendo $1 \mathrm{ml}$ o mínimo necessário. O material foi centrifugado em tubo de polietileno, com tampa de rosca, com 3000 rotações por minutos, durante 15 minutos. Então, o sobrenadante com sedimentos foi desprezado e com uma pipeta de Pasteur de plástico foi coloca em uma lâmina de vidro para a realização do esfregaço. Esse esfregaço foi manipulado dentro da capela de fluxo laminar, com auxílio de um palito de madeira partido ao meio, foi selecionada a porção mais purulenta da amostra e depositada sobre as lâminas de vidros limpas e desengorduradas. A amostra foi colocada até o extremo oposto da lâmina com uma das partes do palito em posição horizontal, seguida de movimentos de um extremo para outro, até se obter o esfregaço homogêneo em 2/3 
da lâmina, sem espaços vazios. Após a confecção do esfregaço, a lâmina foi colocada para secar na capela de fluxo laminar e em seguida fixada sobre a chama do Bico de Bunsen por 3 vezes. Então, foi realizada a leitura dos bacilos em microscópio óptico comum, utilizando objetiva de imersão para visualizar o BAAR. Quando havia presença de BAAR na amostra, eles se tornaram vermelhos devido à retenção da fucsina e foram visualizados microscopicamente, onde o fundo azul no esfregaço, fez o contraste para essa visualização (HOSPITAL DAS CLÍNICAS DA FACULDADE DE MEDICINA DE RIBEIRÃO PRETO, 2021).

- Culturas: O método consistiu na cultura quantitativa de microrganismo em LBA. Para essa análise, a amostra foi homogeneizada e em seguida, utilizando uma pipeta calibrada de $1 \mathrm{ml}$ e tubo cônico, contendo $9 \mathrm{ml}$ de salina (0,45\%) estéril, a amostra foi separada em duas partes, sendo a primeira $1 / 10$ e a segunda $1 / 100$ da solução inicial. Então, foi semeada a solução 1/100 com o material em campos sobrepostos em Agar Sangue, Agar MacConkey e Agar Chocolate em estrias. As placas semeadas foram colocadas em estufas microbiológicas a temperatura de 35 - 37으 $\mathrm{C}$ por 48 horas. Finalmente, foi realizada a análise e identificação dos organismos das placas após a incubação (HOSPITAL DAS CLÍNICAS DA FACULDADE DE MEDICINA DE RIBEIRÃO PRETO, 2021).

- Cultura para micobactérias: A realização de cultura para micobactérias, por ser mais sensível que a baciloscopia, visou melhorar a sensibilidade do diagnóstico laboratorial de micobacterioses. O princípio do método consistiu na semeadura das amostras clínicas em meios de cultivo específicos para micobactérias, através de métodos clássicos automatizados, para permitir a multiplicação e o isolamento. As amostras foram separadas em volumes idealmente de 5 a $10 \mathrm{ml}$, sendo o volume mínimo necessário de $1 \mathrm{ml}$. O material foi centrifugado em tubo de polietileno com tampa de rosca por 30 minutos e sobrenadante foi desprezado. As amostras foram descontaminadas e semadas com 500 ul das amostras no meio de cultura Lowenstein Jensen no frasco para cultura. Após, as culturas foram incubadas em estufa (35ㅇ) C). Foi realizada a leitura das culturas e os casos suspeitos de crescimento foram confirmados pelo Ziehl - Neelsen. A identificação dos grupos de micobactérias em complexo $M$. tuberculosis e Micobactérias não causadoras de tuberculose foi realizada por teste Imunocromatográfico, $e$ a identificação das espécies de micobactérias não causadoras de tuberculose foi realizada através de 
métodos fenotípicos, moleculares ou combinação de ambos (HOSPITAL DAS CLÍNICAS DA FACULDADE DE MEDICINA DE RIBEIRÃO PRETO, 2021).

- Citologia: Essa análise tem como objetivo determinar a contagem global e diferencial de células presentes em líquidos de efusões. A amostra analisada consistiu em $5 \mathrm{ml}$ do material coletado. $O$ procedimento iniciou-se pela contagem de células em contador automático. Quando a contagem mostrou-se superior a 2 vezes $10^{6}$ células por $\mathrm{ml}$, a concentração foi ajustada para $10^{6}$ células $/ \mathrm{ml}$ e, nos casos nos quais a contagem estava inferior a esse valor, a amostra foi concentrada por centrifugação com 1500 rotações por minutos por 5 minutos. A suspensão foi pipetada e centrifugada em 1000 rotações por minutos durante 2 minutos. Em seguida, as lâminas foram retiradas e coradas, utilizando o aparelho de coloração automática e, finalmente foram realizadas as visualizações (HOSPITAL DAS CLÍNICAS DA FACULDADE DE MEDICINA DE RIBEIRÃO PRETO, 2021).

\subsection{Critérios de inclusões}

Foram incluídos no estudo todos os pacientes que realizaram exames de LBA na Seção de Pneumologia, HCFMRP Campus no período analisado pela pesquisa. Ressalta-se que a técnica empregada nesse período não sofreu modificações, esteve sempre sob supervisão do orientador desse projeto, e foi aplicada por 2 biólogas do laboratório que também não foram substituídas nesse período, além dos mesmos equipamentos terem sido empregados e mantidos de acordo com as suas respectivas rotinas de manutenções periódicas.

\subsection{Critérios de exclusões}

Foram excluídos do estudo os pacientes que apresentam erros no arquivo médico e/ou dados incompletos que não permitam a análise correta das condutas médicas, assim como os pacientes menores de 18 anos e também os que já estavam participando de outras pesquisas, devido possível alteração nos métodos de realização do exame de LBA. 


\subsection{Aspectos éticos}

O presente estudo foi submetido ao Comitê de Ética em Pesquisa do HCFMRP, para a liberação da verificação dos arquivos médicos dos pacientes envolvidos. O estudo respeita o sigilo de seus participantes, de acordo com as normas de pesquisa com seres humanos e obteve o parecer consubstanciado número 3.117.972/2019.

\subsection{Condição orçamentária da pesquisa}

O presente estudo não proporcionou novos gastos, visto tratar-se de um estudo retrospectivo, assim como não contou com nenhum tipo de reembolso aos seus participantes.

\subsection{Dados pesquisados e análises}

O levantamento dos casos teve início pela busca das solicitações para as realizações do LBA, que são feitas por impresso próprio do setor, como consta o modelo no anexo $A$, e que são arquivadas na Seção de Pneumologia. A partir dessas solicitações, consultamos os respectivos arquivos médicos de cada indivíduo, onde fizemos o levantamento dos demais dados: idade, sexo, raça ou cor e comorbidades, compondo os dados gerais.

Os dados específicos, que também foram coletados dos prontuários, contaram com busca das hipóteses clínicas antes da realização do LBA e das condições de coleta de material para exame.

Buscamos também as informações das intercorrências e complicações que aconteceram decorrente à realização da coleta do LBA, para verificarmos a segurança do exame.

Exploramos também a contribuição do LBA para os diagnósticos dos casos pesquisados, onde os dados encontrados foram separados em dois aspectos de desfecho: o efeito diagnóstico do LBA e a mudança de conduta após a realização.

Os casos que apresentaram diagnóstico com auxílio do LBA, sendo esse auxílio a confirmação do diagnóstico investigado pelo LBA ou a exclusão pelo LBA, foram alocados no grupo chamado "LBA com efeito diagnóstico"; os casos que não apresentaram diagnóstico com auxílio do LBA, não sendo o LBA capaz de excluir ou 
diagnosticar a doença investigada, foram alocados no grupo chamado "LBA sem efeito diagnóstico".

Os casos que apresentaram alterações de conduta após a realização do LBA, foram alocados no grupo chamado "Mudança de conduta após LBA" e os casos que não sofreram alterações nas suas condutas terapêuticas após a realização do LBA foram alocados no grupo chamado "Condutas mantidas após LBA".

Outros casos encontrados foram os que não possuíam descrições nos prontuários médicos sobre o diagnóstico ou não em relação ao LBA, sendo assim impossível classificá-los; então, foram alocados no grupo " Não citados".

Essa classificação do desfecho em dois aspectos, ou seja, em relação ao efeito diagnóstico e em relação às mudanças de condutas, se faz necessária devido ao fato de alguns casos já terem suas condutas terapêuticas instituídas com base na hipótese clínica devido à urgência dos sintomas, antes mesmo da realização dos exames específicos.

Todos os dados encontrados foram organizados em nosso banco de dados, como o modelo apresentado no apêndice $A$.

A contribuição do LBA para os desfechos dos casos, nos aspectos de efeito diagnóstico do LBA e conduta após a realização do LBA, foi listada inicialmente de maneira geral e, em seguida, de maneira mais específica, separando-as pelas principais hipóteses clínicas investigadas, sendo elas a tuberculose, as neoplasias, as infecções fúngicas, a PH e a DIP. Então, ainda para essa análise por hipótese diagnóstica, esses dados foram separados em dois grupos, o primeiro contendo os participantes que alcançaram o diagnóstico com a contribuição do laudo da análise de LBA, sendo esse grupo chamado de "Diagnóstico com contribuição da análise de LBA" e, o segundo grupo contendo os participantes que alcançaram o diagnóstico sem a contribuição do laudo da análise de LBA, sendo esse grupo chamado de "Diagnóstico sem contribuição da análise de LBA"

Os valores encontrados, estão demonstrados em forma de tabelas seguidos de análises estatísticas para melhor observação dos dados, como descrito abaixo.

\subsection{Análise estatística}

A análise estatística foi realizada utilizando o software estatístico SPSS Statistic 26. Inicialmente, calculamos as médias, desvios-padrão e porcentagens dos grupos descritos acima, seguido de cálculo de rendimento diagnóstico. 
Para comparamos os grupos da localização do LBA, utilizamos a análise de variância ANOVA one-way seguida do teste de Tukey para comparações múltiplas, com valor de $p<0,05$ adotado como significante e intervalo de confiança (IC) de 95\%. 
5 RESULTADOS 
Foram selecionados, inicialmente, 1000 exames que atendiam aos critérios de inclusão. Dois grupos de paciente foram listados como participantes de protocolos de outras pesquisas, usando métodos diferentes de processamento dos materiais coletados para o LBA, aqui chamados de protocolos de pesquisas A e B, com 66 e 49 participantes, respectivamente, por isso, foram excluídos. Dezessete pacientes, foram excluídos por apresentarem idades inferior a 18 anos. Por tratar-se de pesquisa de revisão, alguns prontuários não foram localizados no arquivo, alguns apresentavamse incompletos e, ainda, alguns pacientes não prosseguiram o tratamento médico, ficando assim, impossível o levantamento dos seus dados. Esses casos somaram 48 exames e estão descritos abaixo e foram chamados de "dados incompletos". Assim, os exames excluídos totalizaram 180. Ao final, 820 exames foram considerados aptos para essa pesquisa e foram incluídos, como demonstrados abaixo.
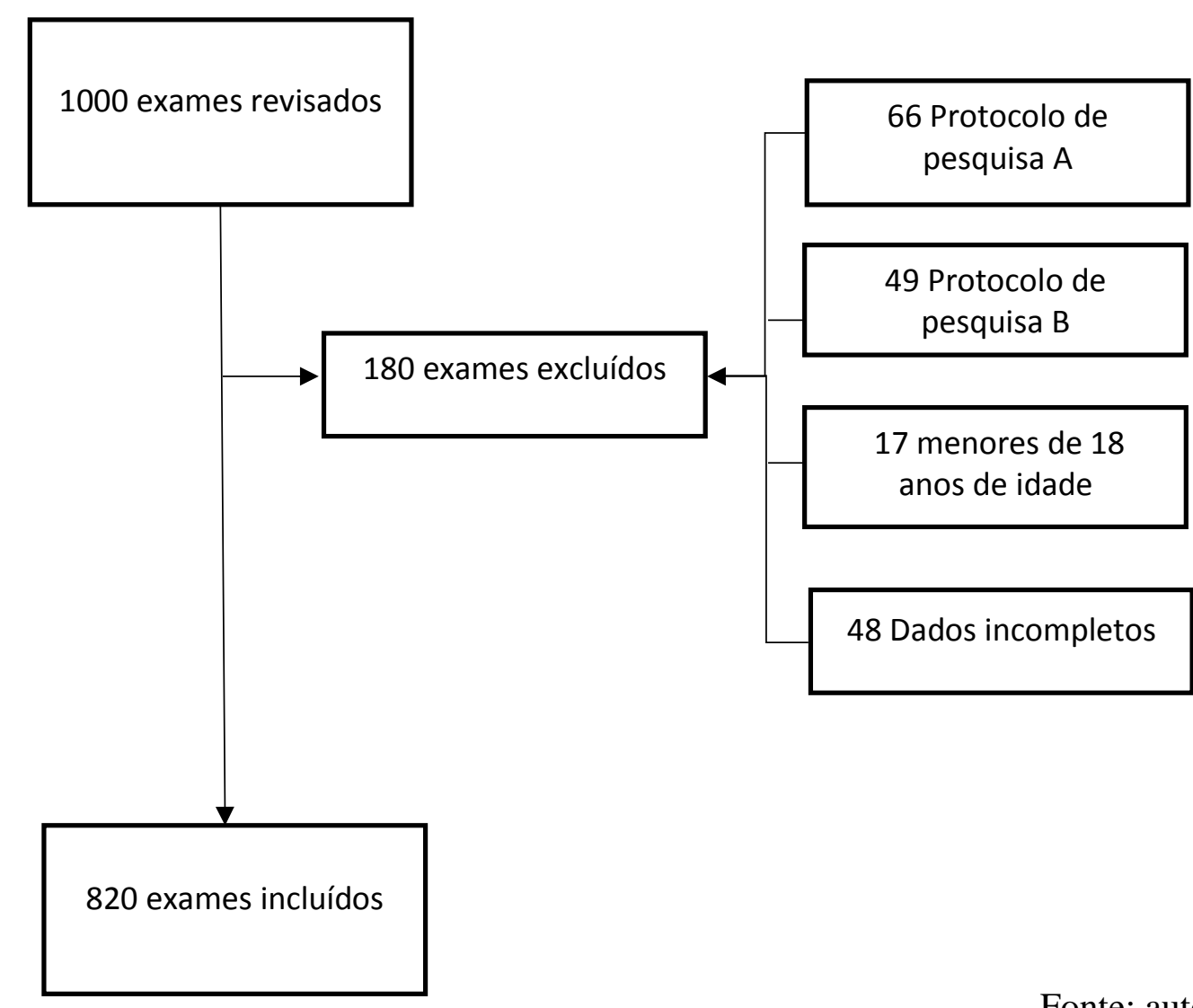

Fonte: autoral

Figura 1. Fluxograma do estudo

Os resultados apresentaram maioria dos participantes do sexo masculino (53,53\%), e média de idade geral de 55 anos com desvio-padrão (DP) de 15,5. 
A cor ou raça autodeclarada branca foi a predominante $(84,64 \%)$, seguida da mulata $(7,68 \%)$, negra ou preta $(7,56 \%)$, e da amarela $(0,12 \%)$.

Comorbidades se mostraram presentes em $78,65 \%$ dos indivíduos, sendo a hipertensão arterial sistêmica (26,83\%) a mais prevalente, seguida de diabetes mellitus (12,68\%), neoplasias (12,56\%), doença do refluxo gastroesofágico $(7,20 \%)$, dislipidemia (6,10\%), insuficiência renal (5,98\%), hipotireoidismo (4,63\%), insuficiência cardíaca $(4,51 \%)$, artrite reumatoide $(4,51 \%)$, doença pulmonar obstrutiva crônica (DPOC) (4,27\%), obesidade (3,17\%), asma (3,05\%), síndrome da imunodeficiência humana adquirida (3,05\%), hepatite ou cirrose hepática $(2,93 \%)$, anemia, desnutrição ou síndrome consumptiva (2,43\%), infarto agudo do miocárdio $(1,83 \%)$, lúpus eritematoso sistêmico (1,83\%) e esclerose sistêmica $(1,10 \%)$. Tais resultados estão demonstrados na Tabela 1. 
Tabela 1 - Dados gerais dos indivíduos submetidos à coleta de LBA

\begin{tabular}{|c|c|c|}
\hline Variáveis & Categorias & Casos (\%) \\
\hline \multirow[t]{2}{*}{ Sexo } & Masculino (\%) & $439(53,53)$ \\
\hline & Feminino (\%) & $381(46,47)$ \\
\hline Idade & Em anos - Média (DP) & $55(15,5)$ \\
\hline \multirow[t]{4}{*}{ Cor ou raça } & Branca & $694(84,64)$ \\
\hline & Mulata & $63(7,68)$ \\
\hline & Negra ou preta & $62(7,56)$ \\
\hline & Amarela & $1(0,12)$ \\
\hline \multirow{2}{*}{$\begin{array}{l}\text { Presença de } \\
\text { comorbidades }\end{array}$} & Indivíduos com comorbidades (\%) & $645(78,65)$ \\
\hline & Indivíduos sem comorbidades (\%) & $175(21,35)$ \\
\hline \multirow{18}{*}{$\begin{array}{c}\text { Principais } \\
\text { comorbidades } \\
\text { encontradas }\end{array}$} & Hipertensão arterial sistêmica & $220(26,83)$ \\
\hline & Diabetes Mellitus & $104(12,68)$ \\
\hline & Neoplasias & $103(12,56)$ \\
\hline & Doença do refluxo gastroesofágico & $59(7,20)$ \\
\hline & Dislipidemia & $50(6,10)$ \\
\hline & Insuficiência renal & $49(5,98)$ \\
\hline & Hipotireoidismo & $38(4,63)$ \\
\hline & Insuficiência cardíaca & $37(4,51)$ \\
\hline & Artrite reumatoide & $37(4,51)$ \\
\hline & DPOC & $35(4,27)$ \\
\hline & Obesidade & $26(3,17)$ \\
\hline & Asma & $25(3,05)$ \\
\hline & Síndrome imunodeficiência humana adquirida & $25(3,05)$ \\
\hline & Hepatite ou cirrose hepática & $24(2,93)$ \\
\hline & Anemia, desnutrição e síndrome consumptiva & $20(2,43)$ \\
\hline & Infarto agudo do miocárdico & $15(1,83)$ \\
\hline & Lúpus eritematoso sistêmico & $15(1,83)$ \\
\hline & Esclerose sistêmica & $9(1,10)$ \\
\hline
\end{tabular}

As hipóteses clínicas para indicação de LBA foram, tuberculose (34,5\%), seguida pelas infecções fúngicas $(24,6 \%)$, infecções bacterianas ou virais $(23,2 \%)$, neoplasias $(19,3 \%)$, PH $(16,5 \%)$, outros $(12,3 \%)$, DIP $(12,1 \%)$, sarcoidose $(4,3 \%)$, fibrose pulmonar $(4,3 \%)$, doenças respiratórias ocupacionais $(1,8 \%)$. Esses dados estão apresentados na Tabela 2. 
Tabela 2 - Hipóteses clínicas para indicação de LBA

\begin{tabular}{cc}
\hline Hipótese clínicas & Casos - $\mathrm{n}(\%)^{*}$ \\
\hline Tuberculose & $324(34,5)$ \\
Infecções fúngicas & $202(24,6)$ \\
Infecções bacterianas ou virais & $190(23,2)$ \\
Neoplasias & $158(19,3)$ \\
PH & $135(16,5)$ \\
DIP & $99(12,1)$ \\
Sarcoidose & $35(4,3)$ \\
Fibrose pulmonar & $35(4,3)$ \\
Doenças respiratórias ocupacionais & $15(1,8)$ \\
Outros & $101(12,3)$ \\
\hline
\end{tabular}

Legendas da Tabela 2: LBA - lavado broncoalveolar; PH - pneumonite de hipersensibilidade; DIP doença intersticial pulmonar; \% - porcentagem. Observações: * Os indivíduos apresentaram uma ou mais hipóteses clínicas, portanto, as somas das ocorrências não totalizam $100 \%$. ${ }^{* *}$ No grupo "outros" encontram-se casos com hipóteses clínicas de toxicidade pulmonar por drogas, colagenose, vasculite, proteinose alveolar, tromboembolismo pulmonar e hemorragia alveolar.

A Tabela 3 traz a situação de coleta de acordo com o local de atendimento do paciente, se ambulatorial, internados em enfermaria, ou unidade de terapia intensiva.

A realização da coleta do material do LBA ao nível ambulatorial foi a predominante $(53,17 \%)$, seguida pela coleta em pacientes internados em enfermaria $(45,61 \%)$ e, por último, a coleta dos pacientes internados em unidade de terapia intensiva (1,22\%).

Tabela 3 - Situação da coleta do LBA

\begin{tabular}{cc}
\hline Local & Número de casos (\%) \\
\hline Ambulatorial & $436(53,17)$ \\
Internação enfermaria & $374(45,61)$ \\
Internação terapia intensiva & $10(1,22)$
\end{tabular}

Legendas da tabela 3: LBA - lavado broncoalveolar; \% - porcentagem.

A Tabela 4 apresenta os dados sobre o segmento pulmonar em que o LBA foi coletado. Nota-se que a maioria foi coletada no brônquio do lobo médio $(26,2 \%)$, seguido do brônquio do lobo inferior direito $(21,2 \%)$, brônquio lobo superior direito $(19,6 \%)$, brônquio do lobo inferior esquerdo $(16,0 \%)$, do lobo superior esquerdo $(8,3 \%)$, brônquio da língula $(4,5 \%)$ e casos que não foram especificados $(4,1 \%)$. 


\begin{tabular}{cc}
\multicolumn{2}{c}{ Tabela 4 - Localização pulmonar da coleta do LBA } \\
\hline Localização da coleta do LBA & Número de casos $(\%)$ \\
\hline BLM & $215(26,2)$ \\
BLID & $174(21,2)$ \\
BLSD & $161(19,6)$ \\
BLIE & $131(16,0)$ \\
BLSE & $68(8,3)$ \\
BL & $37(4,5)$ \\
Não especificado & $34(4,1)$
\end{tabular}

Legenda da Tabela 4: BLM - brônquio do lobo médio; BLID - brônquio do lobo inferior direito; BLSD brônquio do lobo superior direito; BLIE - brônquio do lobo inferior esquerdo; BLSE - brônquio do lobo superior esquerdo; BL - brônquio da língula; \% - porcentagem.

Para melhor avaliação da técnica empregada no procedimento, realizamos a análise do volume de retorno e da relação volume de retorno/infundido (\%) durante a coleta do LBA, no total dos casos e por região pulmonar investigada, para fins comparativos.

Como resultados, o brônquio da língula $(B L)$ teve média de volume infundido de 117,30 $\mathrm{ml}$ (DP de 6,93), volume de retorno de 69,57 ml (DP de 20,76) e volume de retorno em relação ao infundido de 59,19\% (DP de 16,99); o BLM apresentou média de 117,63 $\mathrm{ml}$ (DP de 9,39), volume de retorno de 66,31 $\mathrm{ml}$ (DP de 19,35) e volume de retorno em relação ao infundido de 59,61\% (DP de 16,11); o BLSD apresentou média de 118,70 $\mathrm{ml}$ (DP de 7,67), volume de retorno de 61,96 $\mathrm{ml}$ (DP de 18,98) e volume de retorno em relação ao infundido de $52,40 \%$ (DP de 15,82); o BLSE apresentou média de 117,94 $\mathrm{ml}$ (DP de 7,83), volume de retorno de 59,21 ml (DP de 18,09) e volume de retorno em relação ao infundido de 50,29\% (DP de 15,00); o BLID apresentou média de $118,84 \mathrm{ml}$ (DP de 12,24), volume de retorno de 57,34 ml (DP de 19,46) e volume de retorno em relação ao infundido de 48,60\% (DP de 16,21); o BLIE apresentou média de 119,66 ml (DP de 13,64), volume de retorno de 55,33 ml (DP de 17,92) e volume de retorno em relação ao infundido de $46,69 \%$ (DP de 15,56); as regiões que não foram especificadas apresentaram média de 117,06 ml (DP de 17,15), volume de retorno de $65,62 \mathrm{ml}$ (DP de 20,51) e volume de retorno em relação ao infundido de $57,12 \%$ (DP de 17,42). Esses dados estão na Tabela 5.

Ainda na Tabela 5, estão informações sobre o volume de soro fisiológico infundido para a realização do LBA no total dos casos investigados, o volume de retorno de líquido e a relação entre o volume de LBA e o volume de soro infundido 
que são, respectivamente, 118,41 ml (DP de 10,74), 65,62 ml (DP 20,51), e 52,12\% (DP 16,44). A amostra toda apresentou vitalidade celular média 72\% (DP 13,5).

Tabela 5 - Características técnicas do LBA por localização pulmonar

\begin{tabular}{cccc}
\hline $\begin{array}{c}\text { Localização da } \\
\text { coleta do LBA }\end{array}$ & $\begin{array}{c}\text { Volume } \\
\text { infundido } \\
\text { média em ml } \\
\text { (DP) }\end{array}$ & $\begin{array}{c}\text { Volume de retorno } \\
\text { média em ml (DP) }\end{array}$ & $\begin{array}{c}\text { Volume de retorno em } \\
\text { relação ao infundido (\%) } \\
\text { - Média (DP) }\end{array}$ \\
\hline BL & $117,30(6,93)$ & $69,57(20,76)$ & $59,19(16,99)$ \\
BLM & $117,63(9,39)$ & $66,31(19,35)$ & $56,61(16,11)$ \\
BLSD & $118,70(7,67)$ & $61,96(18,98)$ & $52,40(15,82)$ \\
BLSE & $117,94(7,83)$ & $59,21(18,09)$ & $50,29(15,00)$ \\
BLID & $118,84(12,24)$ & $57,34(19,46)$ & $48,60(16,21)$ \\
BLIE & $119,66(13,64)$ & $55,33(17,92)$ & $46,69(15,56)$ \\
Não & $117,06(17,15)$ & $65,62(20,51)$ & $57,12(17,42)$ \\
especificado & & & \\
Total & $118,41(10,74)$ & $61,33(19,54)$ & $52,12(16,44)$ \\
\hline
\end{tabular}

Legenda da Tabela 5: LBA - lavado brocoalveolar; BLM - brônquio do lobo médio; BLID - brônquio do lobo inferior direito; BLSD - brônquio do lobo superior direito; BLIE - brônquio do lobo inferior esquerdo; BLSE - brônquio do lobo superior esquerdo; BL - brônquio da língula; DP - desvio-padrão; ml - mililitros; $\%$ - porcentagem.

A Tabela 6 traz resultados do teste de Tukey, para fins de comparações entre as localizações pulmonares do LBA. O local para LBA com menor retorno foi o BLIE. Os locais com maiores retornos foram BLM e BL, como apresentado nas Tabelas 5 e 6.

Tabela 6 - Comparações entre localizações pulmonares do LBA

\begin{tabular}{cccc}
\hline $\begin{array}{c}\text { Localização do } \\
\text { LBA }\end{array}$ & $\begin{array}{c}\text { Localização do } \\
\text { LBA }\end{array}$ & $\begin{array}{c}\text { Diferença da } \\
\text { média }\end{array}$ & Significância \\
\hline Não & BLSD & 4,714 & 0,707 \\
especificado & BLSE & 6,824 & 0,396 \\
& BLM & 0,504 & 1,000 \\
& BL & $-2,072$ & 0,998 \\
& BLID & 8,514 & 0,069 \\
BLSD & BLIE & $10,423^{*}$ & 0,013 \\
& Não especificado & $-4,714$ & 0,707 \\
& BLSE & 2,110 & 0,971 \\
& BLM & $-4,210$ & 0,152 \\
& BL & $-6,785$ & 0,233 \\
& BLID & 3,800 & 0,312 \\
& BLIE & $5,709^{*}$ & 0,040 \\
\hline
\end{tabular}




\begin{tabular}{|c|c|c|c|}
\hline \multirow[t]{6}{*}{ BLSE } & $\begin{array}{c}\text { Não } \\
\text { especificado }\end{array}$ & $-6,824$ & 0,396 \\
\hline & BLSD & $-2,110$ & 0,971 \\
\hline & BLM & $-6,320$ & 0,069 \\
\hline & $B L$ & $-8,895$ & 0,094 \\
\hline & BLID & 1,691 & 0,990 \\
\hline & BLIE & 3,599 & 0,742 \\
\hline \multirow[t]{6}{*}{ BLM } & $\begin{array}{c}\text { Não } \\
\text { especificado }\end{array}$ &,- 504 & 1,000 \\
\hline & BLSD & 4,210 & 0,152 \\
\hline & BLSE & 6,320 & 0,069 \\
\hline & $\mathrm{BL}$ & $-2,575$ & 0,972 \\
\hline & BLID & $8,011^{*}$ & 0,000 \\
\hline & BLIE & $9,919^{*}$ & 0,000 \\
\hline \multirow[t]{6}{*}{$\mathrm{BL}$} & $\begin{array}{c}\text { Não } \\
\text { especificado }\end{array}$ & 2,072 & 0,998 \\
\hline & BLSD & 6,785 & 0,233 \\
\hline & BLSE & 8,895 & 0,094 \\
\hline & BLM & 2,575 & 0,972 \\
\hline & BLID & $10,586^{*}$ & 0,005 \\
\hline & BLIE & $12,495^{*}$ & 0,001 \\
\hline \multirow[t]{6}{*}{ BLID } & $\begin{array}{c}\text { Não } \\
\text { especificado }\end{array}$ & $-8,514$ & 0,069 \\
\hline & BLSD & $-3,800$ & 0,312 \\
\hline & BLSE & $-1,691$ & 0,990 \\
\hline & BLM & $-8,011^{*}$ & 0,000 \\
\hline & $\mathrm{BL}$ & $-10,586^{*}$ & 0,005 \\
\hline & BLIE & 1,909 & 0,947 \\
\hline \multirow[t]{6}{*}{ BLIE } & $\begin{array}{c}\text { Não } \\
\text { especificado }\end{array}$ & $-10,423^{*}$ & 0,013 \\
\hline & BLSD & $-5,709^{*}$ & 0,040 \\
\hline & BLSE & $-3,599$ & 0,742 \\
\hline & BLM & $-9,919^{\star}$ & 0,000 \\
\hline & $\mathrm{BL}$ & $-12,495^{*}$ & 0,001 \\
\hline & BLID & $-1,909$ & 0,947 \\
\hline
\end{tabular}

Legenda da Tabela 6: LBA - lavado brocoalveolar; BLM - brônquio do lobo médio; BLID - brônquio do lobo inferior direito; BLSD - brônquio do lobo superior direito; BLIE - brônquio do lobo inferior esquerdo; BLSE - brônquio do lobo superior esquerdo; BL - brônquio da língula.*- A diferença média é significativa no nível 0,05 pelo teste de Tukey.

Alguns casos apresentaram complicações inerentes ao procedimento. As intercorrências que foram descritas nos prontuários analisados, e precisaram de intervenções não programadas estão descritas abaixo na Tabela 7. Foram elas: 
Pneumotórax (2\%), hemorragia grave $(0,4 \%)$ e falha de extubação com necessidade de reintubação $(0,1 \%)$.

Tabela 7 - Complicações decorrentes do procedimento de coleta do LBA

\begin{tabular}{cc}
\hline Complicações & Número de casos (\%) \\
\hline Pneumotórax & $17(2,0)$ \\
Hemorragia grave & $3(0,40)$ \\
Falha de extubação com necessidade de reintubação & $1(0,10)$ \\
Total & $21(2,5)$ \\
\hline
\end{tabular}

Legenda da Tabela 7: LBA - lavado broncoalveolar; \% - porcentagem.

A Tabela 8 apresenta os desfechos após a análise do LBA. Foram separados em três categorias, uma primeira para a análise de condutas após a avaliação dos resultados de LBA (condutas após realização do LBA); uma segunda categoria que versa sobre a contribuição da avaliação do LBA para o diagnóstico final e uma terceira categoria onde as condutas (efeito diagnóstico do LBA) ou o efeito diagnóstico do LBA não foram citados por quem os avaliou (não classificável).

Do total de casos pesquisados, foram encontradas mudanças de condutas em $53,17 \%$. Em $86,34 \%$ dos casos, o LBA se mostrou com efeito para o diagnóstico dos indivíduos, e, em 12,19\%, o LBA apresentou-se sem efeito para o diagnóstico. Em $1,47 \%$ dos casos, a informação sobre o efeito diagnóstico do LBA estava ausente, não sendo possível classificá-la.

Tabela 8 - Contribuição da análise do LBA nas condutas médicas e efeitos diagnósticos

\begin{tabular}{ccc}
\hline & Desfecho dos casos & Número de casos (\%) \\
\hline Condutas após & Mudança de conduta & $436(53,17)$ \\
realização do LBA & Condutas mantidas & $384(46,83)$ \\
\hline Efeito diagnóstico do LBA & Com efeito diagnóstico & $708(86,34)$ \\
& Sem efeito diagnóstico & $100(12,19)$ \\
& Não citados - Não classificável & $12(1,47)$ \\
\hline
\end{tabular}

Legenda da Tabela 8: LBA - lavado broncoalveolar; \% - porcentagem.

A Tabela 9 traz os resultados encontrados em relação à contribuição do LBA para o diagnóstico dos casos com hipótese clínica de tuberculose. Do total de casos avaliados com suspeita de tuberculose, 90,74\% tiveram seus diagnósticos com a contribuição da análise de LBA, 7,72\% tiveram seus diagnósticos sem a contribuição da análise de LBA, e 1,54\% não foram citados em seus prontuários, não sendo possível a sua avaliação. O resultado foi de rendimento diagnóstico de 92,17\%. 
Tabela 9 - Contribuição do LBA no diagnóstico de casos suspeitos de tuberculose

\begin{tabular}{cc}
\hline Categorias & Número de casos (\%) \\
\hline Diagnóstico com contribuição da análise de LBA & $294(90,74)$ \\
Diagnóstico sem contribuição da análise de LBA & $25(7,72)$ \\
Casos não citados & $5(1,54)$ \\
Total de casos suspeitos para tuberculose & $324(100)$
\end{tabular}

Legenda da Tabela 9: LBA - lavado broncoalveolar; \% - porcentagem.

A seguir, na Tabela 10, estão os resultados encontrados em relação à contribuição do LBA para o diagnóstico dos casos com hipótese clínica de neoplasia. Foi observado que o diagnóstico foi obtido com a contribuição da análise de LBA em 3,16\%. E, em $94,94 \%$ dos casos, o diagnóstico foi firmado sem a contribuição da análise de LBA. Em 1,90\% dos casos, as contribuições do LBA não foram citadas, não sendo possível as suas classificações. O rendimento diagnóstico foi de 3,23\%.

Tabela 10: Contribuição do LBA no diagnóstico de casos suspeitos de neoplasias

\begin{tabular}{cc}
\hline Categorias & Número de casos $(\%)$ \\
\hline Diagnóstico com contribuição da análise de LBA & $5(3,16)$ \\
Diagnóstico sem contribução da análise de LBA & $150(94,94)$ \\
Casos não citados & $3(1,90)$ \\
Total de casos suspeitos para neoplasias pulmonares & $158(100)$ \\
Legenda da Tabela 10: LBA - lavado broncoalveolar; \% - porcentagem.
\end{tabular}

A seguir, na Tabela 11, estão os resultados encontrados em relação à contribuição do LBA para o diagnóstico dos casos com hipótese clínica de infecções fúngicas. Do total de casos avaliados com suspeita de infecções fúngicas, 182 casos $(90,10 \%)$ tiveram seus diagnósticos com contribuição da análise de LBA, 8,91\% tiveram seus diagnósticos firmados sem contribuição de LBA e, 0,99\% não foram citados em seus prontuários, não sendo possível a sua avaliação. O resultado foi de rendimento diagnóstico de 91,00\%. 
Tabela 11 - Contribuição do LBA no diagnóstico de casos suspeitos de infecções fúngicas

\begin{tabular}{cc}
\hline Categorias & Número de casos (\%) \\
\hline Diagnóstico com contribuição da análise de LBA & $182(90,10)$ \\
Diagnóstico sem contribuição da análise de LBA & $18(8,91)$ \\
Casos não citados & $2(0,99)$ \\
Total de casos suspeitos para infecções fúngicas & $202(100)$ \\
\hline Legenda da Tabela 11: LBA - lavado broncoalveolar; \% - porcentagem.
\end{tabular}

Abaixo, na Tabela 12, estão os resultados encontrados em relação à contribuição do LBA para o diagnóstico dos casos com hipótese clínica de PH. Dos casos suspeitos para $\mathrm{PH}, 88,89 \%$ tiveram contribuição do LBA para firmar os seus diagnósticos. Em 9,63\% dos casos, o LBA não contribuiu para o diagnóstico, em $1,48 \%$ dos casos, a contribuição do LBA não estava descrita no prontuário médico, não sendo possível sua classificação. O rendimento diagnóstico do LBA para esses casos foi $90,23 \%$.

Tabela 12 - Contribuição do LBA no diagnóstico de casos suspeitos de PH

\begin{tabular}{lc}
\hline Categorias & Número de casos (\%) \\
\hline Diagnóstico com contribuição da análise de LBA & $120(88,89)$ \\
Diagnóstico sem contribuição da análise de LBA & $13(9,63)$ \\
Casos não citados & $2(1,48)$ \\
Total de casos suspeitos para PH & $135(100)$ \\
\hline enda da Tabela 12: LBA - lavado broncoalveolar; \% - porcentagem; PH - pneumonite de \\
\end{tabular}
hipersensibilidade.

A seguir, na Tabela 13, estão os resultados encontrados em relação à contribuição do LBA para o diagnóstico dos casos com hipótese clínica de DIP. Do total de casos avaliados com suspeita de DIP, 73,74\% tiveram seus diagnósticos com contribuição da análise de LBA, 23,23\% tiveram seus diagnósticos sem contribuição da análise de LBA, e, 3,03\% não foram citados em seus prontuários, não sendo possível a sua avaliação. O resultado foi o rendimento diagnóstico de 73,74\%. 
Tabela 13 - Contribuição do LBA no diagnóstico de casos suspeitos de DIP

Categorias Números de casos (\%)

Diagnóstico com contribuição da análise de LBA $73(73,74)$

Diagnóstico sem contribuição da análise de LBA $23(23,23)$

Casos não citados $3(3,03)$

Total de casos suspeitos para DIP $99(100)$

Legenda da Tabela 13: LBA - lavado broncoalveolar; \% - porcentagem; DIP - doença intersticial pulmonar. 
6 DISCUSSÕES 
Em relação às características gerais dos pacientes, observamos predomínio de pacientes do sexo masculino, com $53,53 \%$, sobre o feminino, com $46,47 \%$. Esse fato destoa levemente dos dados encontrados na população geral Brasileira, onde as mulheres representam a maioria com $51,03 \%$ e os homens representam $48,97 \%$ atualmente (IBGE, 2010). A média de idade encontrada foi 55 anos com DP 15,5. O grupo encaixa-se na classificação de adultos, levando-se em consideração a expectativa de vida ao nascer que é de 75,44 anos (IBGE, 2010).

A maioria dos sujeitos analisados nessa pesquisa (78,65\%) possuíam uma ou mais comorbidades. A HAS, com $26,83 \%$ dos casos, e diabetes mellitus, com $12,68 \%$ dos casos, foram as mais encontradas na atual pesquisa, e são esses valores, superiores aos encontrados na literatura por Flor e Campos (2017), que descreveram $7,5 \%$ de prevalência de diabetes mellitus, e encontrados por Fiório et al. (2020), que relataram $23,2 \%$ de prevalência para os casos de HAS.

Esse fato pode ser explicado, devido à pesquisa ser realizada em um hospital de referência de nível terciário, que tem por característica a abordagem de casos alta complexidade e maior gravidade.

A Seção de Pneumologia do HCFMRP, que realiza os exames de LBA, recebe pedidos para esse procedimento dos pacientes do próprio setor e também dos demais setores do hospital, fato esse que justifica a variedade de hipóteses clínicas que motivam a solicitação de broncoscopia com coleta de LBA visando diagnóstico.

Para a coleta do LBA, $53,17 \%$ dos procedimentos foram realizados em atendimento ambulatorial; os pacientes internados nas enfermarias totalizaram $45,61 \%$ das coletas e, apenas, $1,22 \%$ foram coletadas em indivíduos internados em unidades de terapia intensiva.

Em um trabalho realizado por Costa Jr et al. (2018), os autores relataram que dentre os 1949 casos estudados com broncoscopia, 1399 (71,8\%) passaram também por LBA. Do total, $30,7 \%$ dos exames foram realizados na unidade de terapia intensiva, $27,1 \%$ foram realizadas em paciente ambulatoriais e, $23,1 \%$ em paciente de leitos hospitalares. Esse resultado difere do encontrado pelo atual trabalho.

Essa diferença em relação às unidades de terapias intensivas pode ser explicada pelas complexidades dos casos dos pacientes em tratamento nesses setores, onde expor o paciente a mais um procedimento pode ser inviável. Além disso, o fato de o resultado do exame necessitar de alguns dias para a liberação, devido sua fase de processamento, pode limitar os pacientes elegíveis para o exame, tendo-se 
em vista a frequência de casos que cursam com instabilidade e risco de óbito em um curto período.

Outro ponto somado a esses fatores, deve-se a rotina já instituída nas unidades, onde sistemas capazes de verificar e triar precocemente pacientes elegíveis para realizar o LBA poderiam auxiliar no tratamento desses pacientes, uma vez que o LBA pode ser amplamente utilizado para pesquisas infecciosas pulmonares como apresentado aqui e as infecções são detectadas com grande frequência, como demonstrado em pesquisa multicêntrica, realizada em ambientes hospitalares em 88 países por Vicente et al. (2020), que constatou infecções entre 43\% e 60\% dos casos, e que se associavam a alto risco de mortalidade intra-hospitalar, fato que ressalta a necessidade de seu controle.

Os instrumentos diagnósticos para pesquisas infecciosas são relevantes e aliados aos desfechos terapêuticos desse grupo de pacientes.

Visando a qualidade dos exames realizados pela Seção de Pneumologia do HCRP, alguns pontos foram abordados.

Primeiramente, como já citado para fins de descrição dos métodos dessa pesquisa, a técnica empregada nesse período em que foram pesquisados os exames de LBA não sofreu modificações. Apesar de tratar-se de um hospital universitário, que conta com o fluxo constante de residentes, todos os procedimentos de coleta do material do LBA são realizados com a participação dos médicos assistentes do serviço que seguem a padronização definida para a técnica descrita acima.

Outro fator importante é que as análises dos materiais coletados foram realizadas por apenas duas biólogas do laboratório durante todo o período; assim como os tipos de equipamentos utilizados nesse processo também foram mantidos e seguiram as suas respectivas rotinas de manutenções periódicas.

Finalmente, todas as etapas do LBA, de coleta e processamento laboratorial do material estiveram sempre sob a mesma supervisão, que foi também o orientador dessa pesquisa. Assim, apesar de tratar-se de uma pesquisa retrospectiva, as realizações dos exames apresentaram o mesmo protocolo desde o seu início.

Ainda sobre a qualidade dos exames, o volume infundido, o volume obtido no retorno e a localização pulmonar na qual foi realizada a coleta do material do LBA, também devem ser consideradas. Como média geral, o volume obtido no retorno foi de 52,12\% (DP de 16,44) do volume infundido, o que é satisfatório para a análise laboratorial e, compatível com os dados encontrados na literatura, como relatado no 
trabalho realizado por Radhakrishna et al. (2015) sobre técnicas de realização do LBA, que apontou que a quantidade de retorno do LBA foi em média de $40 \%$, quando utilizado a sucção de parede e $42 \%$ quando utilizada a sucção da seringa; essa diferença encontrada não se mostrou relevante quando comparada as duas técnicas. Nesse mesmo trabalho, verificou-se ainda que o BLM esteve associado ao maior volume de retorno do líquido infundido e deve ser usado idealmente para a coleta de LBA, quando não há suspeita em região pulmonar específica.

No LBA, é recomendado que, para uma amostragem ideal dos espaços aéreos distais, o volume de retorno deva ser maior ou igual a $30 \%$ do volume infundido. Quando esse valor se apresenta inferior a $30 \%$, pode fornecer um diferencial de células enganoso, o que fica ainda mais evidente se esse valor for inferior a $10 \%$ do volume total instilado (MEYER, 2012).

No presente trabalho, podemos observar que esse volume de retorno variou de acordo com a região pulmonar na qual foi infundido e ainda que o BLM foi o mais investigado, contando com $26,2 \%$ dos casos e retorno de $56,61 \%$ (DP de 16,11 ) do volume infundido.

Esse fato é relevante porque, como discutido por Radhakrishna et al. (2015), o resultado do LBA sofre interferência da região pulmonar submetida ao lavado, sendo recomendada a escolha do local após avaliação de exame de imagem e, em casos no quais não há diferenciação no exame de imagem, recomenda-se a coleta do LBA preferencialmente no lobo médio, devido ao fato dele apresentar maior retorno do líquido do LBA para a análise. Em nossa amostra, o brônquio da língula, que é o equivalente topográfico no lado esquerdo, também se destacou com maiores retornos.

Contamos com uma grande variedade de hipóteses clínicas investigadas. Os casos mais investigados foram os com hipótese clínica de tuberculose $(34,5 \%)$, seguida pelas infecções fúngicas $(24,6 \%)$ e infecções bacterianas $(23,2 \%)$, mostrando o emprego do LBA nas investigações das infecções pulmonares.

A tuberculose foi a hipótese clínica principal em 34,5\% dos casos investigados no presente trabalho. Esse valor expressivo pode ser explicado pelo fato de a tuberculose representar um antigo e recorrente desafio à saúde desde, possivelmente, a pré-história humana (BARBERIS, BRAGAZZI, GALLUZZO, MARTINI; 2017). Assim, com o desenvolver da tecnologia, testes variados para indicar a presença do Mtb foram desenvolvidos com diferentes recursos e consequentemente diferentes rendimentos diagnósticos e custos. 
Uma pesquisa realizada por Lui et al. (2018) com 1539 pacientes suspeitos de tuberculose mostrou que o LBA teve maior sensibilidade para detecção do Mtb $(63,4 \%)$ do que o escarro $(43,5 \%)$. Nos casos de pacientes com escarro negativo, menores de 35 anos, com liberação de interferon-gama e presença de cavidades pulmonares, houve $84,8 \%$ de positividade para Mtb no LBA, aumentando a proporção de detecção para o diagnóstico.

No atual trabalho, também foi encontrado um valor expressivo do LBA para contribuir com o diagnóstico desses pacientes, sendo que em $90,74 \%$ dos casos foi feito o diagnóstico positivo ou negativo para Mtb pelo LBA, contra $7,72 \%$ dos casos nos quais foram necessários outros exames para esse mesmo desfecho e 1,54\% dos casos que não foram citados nos prontuários, por isso, não podemos analisá-los nesse sentido. O LBA mostrou-se útil para amparar o diagnóstico dos casos suspeitos de tuberculose.

Houve suspeita clínica de infecção fúngica em 24,6\% dos indivíduos submetidos a broncoscopia. O LBA foi útil para o diagnóstico em $90,10 \%$. Os casos em que o LBA não teve participação para diagnóstico somaram 8,91\%, e em 0,99\% dos casos não havia relatos sobre base da conclusão diagnóstica, não sendo possível essa avaliação.

As infecções fúngicas representam uma grave ameaça à saúde, especialmente quando acometem pacientes com comprometimento imunológico (LI, LU; MENG, 2019).

As últimas décadas contaram com um grande desenvolvimento nos conhecimentos dos fungos, nos aspectos sobre a composição de Aspergillus, fungos endêmicos, Histoplasma capsulatum e Blastomyces dermatitidis, que apresentam capacidade para causar distúrbios graves à saúde. Com isso, testes de diagnóstico para detectar esses fungos se desenvolveram (SMITH, KAUFFMAN; 2012).

Em um estudo com 209 participantes que foi realizado por Shi et al. (2020) sobre os principais patógenos de infecção pulmonar primária em pacientes com síndrome da imunodeficiência adquirida, foram encontrados como agentes causadores o citomegalovírus, Mtb, fungos e Pneumocystis carinii, que são potencialmente causadores de impacto grave à esses pacientes. Esse estudo também constatou que a broncoscopia e o LBA foram importantes no diagnóstico desses microrganismos e direcionamento dos respectivos tratamentos. O LBA se mostrou útil 
para identificar e guiar tratamentos desses agentes também em outros trabalhos (SMITH, KAUFFMAN; 2012).

Em 23,2\% dos nossos casos investigados, a hipótese clínica pesquisada foi infecção bacteriana. Nesse grupo de participantes, dentre os casos que apresentaram resultados positivos para bactérias nas análises de LBA, a diferenciação microbiana apresentou como agentes causadores a Escherichia Coli, em 4 casos; Acinetobacter, em 1 caso; Serratia marcescens, em 1 caso; Sthaphylococcus haemolyticus, em 1 caso; Stenotrophomonas maltophilia, em 3 casos; Pseudomonas, em 1 caso; Klebsiella pneumoniae, em 1 caso; Enterobacter cloacae complex, em 1 caso; Pseudomonas aeruginosa, em 10 casos; Streptococcus pneumoniae, em 3 casos; Pseudomonas fluorescens, em 1 caso; Sthaphylococcus aureus, em 17 casos; Sthaphylococcus pneumoniae, em 1 caso; Streptococcus agalactiae, em 1 caso; Acinetobacter baumannii, em 4 casos; Enterococcus faecalis, em 1 caso; Enterococcus faecalis e Klebisiella pneumoniae, em 1 caso; Moraxella catarrhalis, em 3 casos; Pseudomonas aeruginosa e Sthaphylococcus aureus, em 1 caso; Corynebacterium sp, em 1 caso; Klebsiella oxytoca, em 1 caso; Sthapylococcus epidermidis, em 1 caso; Klebsiella, em 1 caso; Acinetobacter Iwoffii, em 1 caso; e Klebsiella pneumoniae e Serratia marcescens, em 1 caso.

Um estudo realizado com pacientes hospitalizados e com suspeita de síndrome da angústia respiratória aguda realizou LBA nos pacientes que apresentaram resultados microbianos negativos nos testes de aspirado de secreção traqueal ou escarro. Em 55,7\% dos casos, o LBA identificou patógenos bacterianos, virais, outros ou combinados, mostrando assim a capacidade do LBA em identificar potenciais patógenos (KAO et al., 2017).

Uma meta-análise realizada para caracterizar e comparar a acurácia do exame físico, radiografia, aspirado da secreção traqueal, culturas de amostras do escovado brônquico e do LBA em auxiliar o diagnóstico de pneumonia associada à ventilação mecânica em pacientes adultos, encontrou como resultados baixas sensibilidade e especificidade combinadas para os achados do exame físico, com valores variados entre eles, o aspirado da secreção traqueal com sensibilidade de $75,7 \%$ e especificidade de 67,9\%, o escovado brônquico com sensibilidade de $61,4 \%$ e especificidade de $76,5 \%$, e o LBA com sensibilidade de $71,6 \%$ e especificidades de $76,9 \%$. Mesmo com o LBA mostrando valores mais elevados de sensibilidade e especificidade em relação aos demais testes, os autores concluíram que o diagnóstico 
seguro, deve ser baseado na soma dos fatores, ou seja, em resultados dos exames laboratoriais, exame físico, exames de imagens, etc. (FERNANDO et al.; 2020). Assim, triar pacientes que possam apresentar melhores rendimentos diagnósticos com cada exame e considerar os demais fatores, pode ser uma opção de melhor aproveitamento dos recursos e de tempo.

Em outra pesquisa, diferentemente do nosso estudo, foram investigados pacientes pediátricos, buscando-se determinar a utilidade da identificação dos agentes causadores de pneumonia pelo LBA. Foram encontradas bactérias aeróbias isoladas em $42 \%$ dos casos e bactérias anaeróbias em $24 \%$ deles. As bactérias isoladas mais frequentemente foram Streptococcus viridians, Pseudomonas aeruginosa e Staphylococcus aureus, sendo o LBA capaz de guiar modificações nos regimes de antibióticos em $55,3 \%$ dos casos para os casos de cultura aeróbia positiva e 9,6\% nos casos com cultura aeróbica negativa. Esse resultado foi descrito como alta frequência de terapia bem-sucedida relacionada ao LBA, quando considerado os casos de cultura aeróbia positiva (TSAI et al., 2017).

Em relação às investigações de neoplasias no atual trabalho, foi encontrado LBA indicativo do diagnóstico em 19,3\% dos casos.

Apesar de apresentar uma indicação mais limitada para a realização do LBA na investigação do diagnóstico de neoplasias pulmonares, essa hipótese diagnóstica continua sendo investigada através desse recurso, ainda que como exame complementar (GRÜNEWALDT et al., 2017).

Grünewaldt et al. (2017) analisou lavados broncoalveolares de 38 pacientes com neoplasias de pulmão com diagnóstico recente e, através de análise citológica encontrou evidências de células neoplásicas em 11 amostras (29\%). Em 10 amostras (26\%), o LBA foi negativo e 17 amostras (45\%) não foram submetidas à análise citológica.

Dos casos com suspeita de neoplasia que foram encontrados pelo atual trabalho, o diagnóstico foi confirmado pelo LBA em apenas 3,16\% dos casos. Em 94,94\%, o diagnóstico foi realizado por outros exames e apenas em 1,90\% dos casos não havia citação no prontuário médico, inviabilizando a avaliação.

Nenhum caso de neoplasia pulmonar foi investigado exclusivamente pelo LBA, então, os casos em que não foram encontradas evidências de células neoplásicas no LBA não foram considerados como livres da doença, mas se deu continuidade à 
investigação da hipótese diagnóstica por outros métodos diagnósticos como a biópsia pulmonar.

Em um trabalho realizado por Grünewaldt et al. (2017), os autores não encontraram padrões celulares típicos no LBA de pacientes com neoplasias pulmonares.

Outros estudos também verificaram a utilidade do LBA para investigação de neoplasias pulmonares. Mlika et al. (2012), analisando 118 lavados broncoalveolares, encontraram sensibilidade de 56\% e especificidade de 90\%. Bezel et al. (2016), avaliando o diagnóstico de câncer de pulmão através do LBA, encontraram sensibilidade do LBA de $29 \%$, com rendimento diagnóstico de $46 \%$ e evidenciaram ainda que em apenas $1 \%$ dos casos de câncer foram feitos diagnósticos exclusivamente pelo LBA, evidenciando o baixo valor diagnóstico do LBA para neoplasias pulmonares.

Tomar et al. (2016) realizaram uma pesquisa comparando a eficácia diagnóstica para a detecção de células neoplásicas no LBA, no escovado brônquico e na citologia aspirativa por agulha fina da lesão. A sensibilidade encontrada para o LBA, o escovado brônquico e a citologia aspirativa por agulha fina foi de $47,61 \%$, $65,07 \%$ e $88,88 \%$, respectivamente, e a especificidade do LBA, escovado brônquico e citologia foram de $75 \%, 75 \%$ e $100 \%$ respectivamente, mostrando este último se destacando entre as três técnicas e demonstrando a necessidade de cautela no uso do LBA para essa finalidade.

Assim, o uso do LBA para fins diagnósticos de neoplasias, não deve ser considerado como método principal ou exclusivo.

Os casos descritos como hipóteses clínicas de $\mathrm{PH}$ representam 16,5\% do total pesquisado nesse trabalho. Desse total, $88,89 \%$ dos casos contaram com o auxílio do LBA para sua resolução, 9,63\% obtiveram diagnóstico com auxílio de outros exames, e, apenas 1,48\% não apresentaram descrições sobre os desfechos desses casos, não podendo assim serem analisados nesse trabalho.

A PH apresenta uma variedade de propostas em relação à sua definição, diagnóstico e abordagem clínica. Essa falta de consenso motivou a criação recente de uma diretriz para amparar essas questões. Nesse amplo trabalho, ficou recomendado que o diagnóstico de $\mathrm{PH}$, em casos não fibrótico e fibrótico, deve ser amparados pela realização do LBA com a contagem de células de linfócitos, porém, não como exame único (RAGHU et al.; 2020). 
Adams et al. (2018) pesquisaram 155 pacientes, onde encontraram como resultado uma média de linfócitos no LBA maior na PH inflamatória em comparação com o PH fibrótica e constataram que a realização da biópsia transbrônquica somada ao LBA, aumentou significativamente o rendimento diagnóstico da $\mathrm{PH}$, sugerindo que a análise combinada é um recurso útil no seu diagnóstico, ainda podem diminuir a necessidade da realização da biópsia pulmonar cirúrgica, procedimento de maior porte e risco.

Barber et al. (2019) realizaram um levantamento com especialistas para se estabelecer a causa da $\mathrm{PH}$. Nesse levantamento, os participantes estimaram que $20 \%$ dos pacientes em seus serviços de DPI possuíam PH como diagnóstico final, sendo detectada a causa em $32 \%$ dos casos. Os aspectos considerados para as classificações foram as características radiológicas, as tomografias de alta resolução e a duração dos sintomas. Também foi relatado que os casos com o diagnóstico de $\mathrm{PH}$ confirmada contaram com a realização do LBA em $40 \%$ das vezes e com a biópsia cirúrgica em 10\%, mostrando assim, a utilidade de se somar o LBA na pesquisa dos casos com hipótese diagnóstica de $\mathrm{PH}$.

Salisbury et al. (2016) realizaram uma pesquisa em busca de meios diagnósticos e tratamentos disponíveis para $\mathrm{PH}$ e $\mathrm{PH}$ fibrótica, onde encontraram indicações relevantes para a realização do LBA como uma opção de análise celular em casos que permanecem o diagnóstico duvidoso mesmo após a realização da tomografia de alta resolução de tórax, associados à história clínica, juntamente com a biópsia transbrônquica, criobiópsia transbrônquica e a biópsia pulmonar cirúrgica.

O LBA tem suas vantagens em relação a outras técnicas de análises celulares, principalmente por tratar-se de uma coleta de material menos traumática ao tecido pulmonar, entretanto, também possui suas limitações diagnósticas referentes ao local da amostragem, necessidade da manutenção da qualidade da armazenagem e processamento do material, como já citado anteriormente.

Em nenhum dos trabalhos analisados, o LBA foi indicado como exame único para diagnóstico de $\mathrm{PH}$. Isso ocorre devido à complexidade da $\mathrm{PH}$, necessidade de diagnósticos diferenciais específicos a cada caso, evolução da própria doença e ainda, à gravidade inerente a cada paciente. Entretanto, em todos os trabalhos, o LBA foi capaz de contribuir para o diagnóstico de $\mathrm{PH}$ quando indicado com base na investigação prévia dos indivíduos suspeitos. 
Em relação aos casos pesquisados como hipóteses clínicas de DIP, encontramos o total de $12,1 \%$ dos casos, onde 73,74\% obtiveram diagnóstico com auxílio do LBA, 23,23\% obtiveram diagnóstico através de outros exames e 3,03\% não tiveram o motivo de sua resolução relatada nos prontuários médicos, não sendo possível suas avaliações no nosso trabalho.

Adams et al. (2020) realizaram um estudo de coorte retrospectivo para identificar os fatores que estiveram associados à mudança no diagnóstico de DPI antes e após a realização do LBA e da biópsia transbrônquica. Após observarem 245 pacientes, verificaram que o LBA foi capaz de alterar o diagnóstico em 23,7\% dos casos e, quando foi adicionada a biópsia transbrônquica aos resultados do LBA, 0 rendimento diagnóstico aumentou de 21,8 para $34,1 \%$. O atual trabalho não contabilizou especificamente as mudanças diagnósticas de DIP após o LBA, e sim os casos que obtiveram contribuição ou não do LBA para o seu diagnóstico, essa diferença de métodos pode explicar a diferença nos valores encontrados. Entretanto, em ambos trabalhos, os valores foram expressivos e favoráveis à contribuição do LBA na investigação diagnóstica da DIP, apesar da complexidade desse diagnóstico.

Chang et al. (2020) avaliaram 184 pacientes para definirem a utilidade clínica do LBA em pacientes que apresentaram sinais de DPI radiograficamente. Os resultados foram bastante interessantes. Vinte e três casos tiveram diagnósticos finais infecciosos, 102 casos não infecciosos, 19 casos de etiologias mistas e 40 casos não diagnosticados. Quanto ao desfecho do rendimento diagnóstico, os resultados foram de $60,6 \%$ nos casos de pacientes de terapia intensiva, 69,7\% nos casos de pacientes internados em enfermarias gerais e de $21,6 \%$ em pacientes de atendimento ambulatorial. De maneira geral, o rendimento diagnóstico foi de 57,1\%. Com esses achados, os autores concluíram que o LBA foi útil para o diagnóstico de DIP, especialmente em pacientes internados em terapia intensiva.

A presente amostra de pacientes internados em terapia intensiva, de maneira geral, foi insuficiente para estabelecer comparações específicas. Essa questão se deve principalmente à rotina da terapia intensiva e características dos seus pacientes em nosso hospital, como discutimos anteriormente.

O aspecto das sobreposições de hipóteses diagnósticas como citado por Chang et al. (2020) e aqui descrito acima, também é bastante relevante para nossa população, sendo que, devido à gravidade dos pacientes, evoluções dos casos e características especificas à cada doença, esse fenômeno se mostra presente. $O$ fato 
é que o LBA se apresentou eficaz para elucidar os quadros apresentados e, assim, contribuir com o diagnóstico desses pacientes em $73,73 \%$ dos casos.

Efared et al. (2017) buscaram avaliar o valor diagnóstico do LBA no manejo da DPI. Para isso, realizaram um estudo com 151 pacientes com suspeita de DIP que realizaram LBA para a análise da sua citologia. Não foram encontradas diferenças na contagem celular do LBA entre os diferentes tipos de DIP, assim, o LBA não se confirmou como adequado para se distinguir os diferentes tipos de DIP, reforçando a necessidade da associação de outros métodos diagnósticos.

A DIP abrange um complexo e heterogêneo grupo de doenças pulmonares, o que torna seu diagnóstico difícil e só possível após o levantamento das características clínicas, biológicas, radiográficas, histológicas e citológicas do paciente (EFARED et al., 2017).

Este levantamento verificou que, no cenário da DIP, o LBA se mostrou útil para somar dados no processo de investigação de diagnóstico.

Outras doenças que foram encontradas em menor quantidade foram a fibrose pulmonar, a sarcoidose e as doenças ocupacionais, com $4,3 \%, 4,3 \%$ e $1,8 \%$ dos casos respectivamente.

Petrosyan et al. (2015) buscaram observar o manejo de pacientes com fibrose pulmonar idiopática com possíveis exacerbações, para assim, detectar o papel do LBA nessa população. Constataram que o LBA também precisa estar associado à investigação dos dados históricos e clínicos para se verificar os casos com potenciais benefícios da realização do LBA.

Novosadova et al. (2019) realizaram uma comparação de fenótipos de linfócitos do LBA entre pacientes não fumantes com sarcoidose e outras doenças pulmonares. Como resultado, constataram um perfil celular típico de LBA, o que o torna útil como recurso para essa população, porém, sugerem mais estudos para definir a sua utilidade em casos com fatores adicionais como o tabagismo ou tratamentos.

A atual pesquisa apresentou diferenças no processamento do LBA em relação ao realizado por Novosadova et al. (2019), sendo que não contamos com a avaliação mais detalhada da relação dos marcadores de células $\mathrm{CD} 3{ }^{+}, \mathrm{CD} 3{ }^{+} \mathrm{CD} 4^{+} \mathrm{e}$ CD3 + CD8 +, ou seja, contamos com uma avaliação menos detalhada nesse aspecto.

O perfil do LBA em pacientes expostos ao amianto foi pouco investigado até o momento. Um estudo recente realizado por Sartorelli et al. (2020) avaliou o perfil das células do LBA nesse grupo de pacientes. Como resultado, foi encontrado que o 
padrão celular do LBA não parece estar relacionado aos biomarcadores de exposição ao amianto como os corpos de amianto e concentração de fibra de amianto no LBA, porém, a carga de amianto pode ser observada no LBA através da visualização dos corpos de amianto, o que também foi encontrado por Kido et al. (2017), que concluíram que a avaliação do LBA para a detecção de amianto, ferro e fósforo são muito úteis na avaliação à exposição ocupacional.

No atual trabalho, a amostra de pacientes para fibrose pulmonar, sarcoidose e doenças ocupacionais não nos permite fazer considerações mais amplas por tratarse de grupos pequenos.

Outro fator importante para a realização do LBA é a sua segurança para o paciente.

A coleta do material para o processamento laboratorial do LBA mostrou-se segura, apresentando apenas $2,5 \%$ de intercorrências.

É possível que as intercorrências encontradas no presente levantamento sejam, em sua maioria, decorrentes de procedimentos que foram realizados em conjunto com a coleta do LBA, como a própria broncoscopia. Devido ao formato desse estudo, não foi possível tratar de forma isolada e confiável esses fatores. Entretanto, essas intercorrências evoluíram, em sua maioria, sem necessidade de novas intervenções, ou seja, com resolução espontânea.

A literatura relata situações de intercorrências ocorridas na broncoscopia, após LBA e ainda secundárias a biópsia.

Hellyer et al. (2020) encontraram queda da saturação sanguínea de oxigênio com necessidade de um pequeno aumento das necessidades de oxigênio suplementar de maneira transitória. No nosso trabalho, esse tipo de intercorrência foi encontrada em apenas $3,7 \%$ dos casos e evoluíram com melhora e recuperação aos valores iniciais momentos após o término do procedimento.

Costa Jr et al. (2018) relataram as intercorrências encontradas em suas pesquisas com 1949 pacientes que realizaram broncoscopia flexível, biópsia e LBA. Foram relatados os eventos adversos graves que precisaram de intervenções adicionais. Esses eventos somaram $0,5 \%$, sendo $0,4 \%$ de pneumotórax e $0,1 \%$ de hemorragia grave com óbito, sendo esses valores considerados de risco mínimo.

Jacomelli et al. (2020) analisaram recentemente, as complicações relacionadas à broncoscopia flexível e procedimentos decorrentes dela, ou seja, o LBA, as biópsias, o escovado brônquico e a punção aspirativa por agulha fina. Foram consideradas para 
aquele estudo, as complicações apresentadas durante o procedimento e até 2 horas após o seu término e, nessas condições, encontraram 5,3\% dos casos de intercorrências, sendo o sangramento de moderado a acentuado volume presente em $2,2 \%$ dos casos, pneumotórax em $0,7 \%$, broncoespasmo em $0,8 \%$, complicações gerais, tais como hipoxemia, agitação psicomotora, arritmias, vômitos e hipotensão em $1,6 \%$, e parada cardiorrespiratória revertida em $0,03 \%$. Foram analisados também, como grupo separado, os pacientes submetidos às biópsias, escovado brônquico e punção aspirativa por agulha fina, sendo que nesse grupo, as intercorrências foram de $4,3 \%$ e, quando analisados os pacientes submetidos às biópsias transbrônquicas, as intercorrências de pneumotórax foram de $2,0 \%$. Os autores consideraram os procedimentos seguros e com baixo índice de complicações. Esses achados são compatíveis com os encontrados no atual trabalho, como descrito acima.

Apesar das variações dos valores encontrados como intercorrências, as taxas se mantiveram baixas, por isso, preconizam a segurança do procedimento.

O principal ponto do presente trabalho, foi observar o desfecho dos casos que analisamos em relação às mudanças de condutas e à capacidade do LBA em produzir efeitos diagnósticos. De maneira geral, o que encontramos como resultado foram mudanças de condutas em $53,17 \%$ e efeito diagnóstico do LBA em $86,34 \%$ dos casos.

As mudanças de condutas após a realização do LBA, diferentemente da capacidade do LBA em diagnosticar diferentes condições pulmonares, é um tema pouco explorado na literatura e seria de grande importância para se elucidar as demais vertentes do LBA e explorar ao máximo o seu potencial.

Entretanto, o LBA foi bastante relevante para os diagnósticos dos casos aqui estudados. O fato de o LBA ter sua contribuição para o diagnóstico e não estar exatamente ligado às mudanças de condutas, pode ser explicado pelo fato de alguns tratamentos serem iniciados antes da liberação dos resultados dos exames devido à gravidade dos sintomas e, nesses casos, o LBA auxiliou o diagnóstico e embasou a manutenção das condutas já empregadas. 
7 CONCLUSÕES 
Concluímos que o LBA se afirma como recurso para o diagnóstico e consequentemente para a condução dos casos das doenças pulmonares pesquisadas no nosso trabalho.

O uso do LBA para a investigação de infecções pulmonares se destacou no atual trabalho, possibilitando os seus tratamentos. Em contraponto, a pesquisa de neoplasias através do LBA pouco pôde contribuir com a investigação desses casos.

A coleta do LBA pela broncoscopia se mostrou segura com uma pequena parcela de complicações graves oriundas do procedimento empregado e que estão justificadas pelos benefícios do exame descritos aqui.

Visando contribuir com o aproveitamento de recursos do serviço de saúde, esses dados reforçam a necessidade de se implementar o estudo do lavado em hospitais e locais de atendimento em que a broncoscopia é rotineiramente utilizada. Pois, além dos dados obtidos pela observação endobrônquica, biópsia e aspirado de secreções, a técnica do LBA contribui para decisões médicas. Não basta apenas obter o material, a análise microbiológica e citológica são necessidades para se aplicar o método e para se obter os melhores resultados possíveis. 
REFERÊNCIAS 
ADAMS, T. N. et al. Utility of Bronchoalveolar Lavage and Transbronchial Biopsy in Patients with Hypersensitivity Pneumonitis. Lung, v. 196, n. 5, p. 617-622, Out.2018.

ADAMS, T. N. et al. Utility of Bronchoalveolar Lavage and Transbronchial Biopsy in Patients with Interstitial Lung Disease. Lung, v. 198, n. 5, Out. 2020.

AHMAD, M. et al. Diagnostic value of bronchoalveolar lavage in the subset of patients with negative sputum/smear and mycobacterial culture and a suspicion of pulmonary tuberculosis. International Journal of Infectious Diseases, p. 96-101, Mar. 2019.

AKYIL, F. T. et al. Correlation between the Diagnostic Yield from the Bronchoalveolar Lavage Fluid Analysis and Clinicoradiological Findings in Sarcoidosis. Turk Thorac J. p. 21-26, Jan. 2020.

ALEKSONIENE, R. et al. Relationship between radiologic patterns, pulmonary function values and bronchoalveolar lavage fluid cells in newly diagnosed sarcoidosis. Journal of Thoracic Disease, v. 9, n. 1, Jan. 2017. Disponível em: https://jtd.amegroups.com/article/view/11629. Acesso em: 25 fev. 2021.

BARBER, C. M. et al. Identifying causation in hypersensitivity pneumonitis: a British perspective. BMJ Open Respir Res., Dez. 2019.

BARBERIS, I. et al. The history of tuberculosis: from the first historical records to the isolation of Koch's bacillus. J. Prev. Med. Hyg., p. 9-12, Mar. 2017.

BEZEL, P. et al. Diagnostic Value of Bronchoalveolar Lavage for Diagnosis of Suspected Peripheral Lung Cancer. Clin Lung Cancer, p. 151-156, Set. 2016.

BLANC, P. D. et al. The Occupational Burden of Nonmalignant Respiratory Diseases. American Journal of Respiratory and Critical Care Medicine, p. 13121334, Jun. 2019.

BRASIL. Governo do Brasil. Disponível em:

http://www.brasil.gov.br/saude/2009/12/sus. Acesso em: 30 abr. 2018.

BRASIL. Ministério da Saúde. Disponível em:http://portalms.saude.gov.br/sistemaunico-de-saude/estrutura-do-sus/770-sistema-nacional-de-saude/40317-atencaoespecializada. Acesso em: 30 abr. 2018.

BRASIL. Ministério da Saúde. Secretaria de Ciência, Tecnologia e Insumos Estratégicos. Departamento de Ciência e Tecnologia. Diretrizes metodológicas:

Diretriz de Avaliação Econômica - 2. ed. Brasília, 2014. 
CHANG, S. L. et al. Clinical usefulness of bronchoalveolar lavage in patients with interstitial lung diseases: a pilot study. J Thorac Dis., p. 3125-3134, Jun. 2020.

CHIN, K. L. et al. Pulmonary non-tuberculous mycobacterial infections: current state and future management. European Journal of Clinical Microbiology \& Infectious Diseases, v. 39, p. 799-826, 2020.

$\mathrm{CHOO}, \mathrm{R}$. et al. Utility of bronchoalveolar lavage in the management of immunocompromised patients presenting with lung infiltrates. J. Thorac. Dis., Hong Kong, Fev. 2019.

COSTA JR., A. D. S. et al. Indications, clinical outcomes and complications of 1,949 flexible bronchoscopies. Einstein, São Paulo, Nov. 2018.

COWMAN, S. et al. Non-tuberculous mycobacterial pulmonary disease. European Respiratory Journal, 2019.

DELIGHT, N.; SACHS, H. Pneumoconiosis. StatPearls, Ago. 2020. Treasure Island. 2021.

DU RAND, I. A. et al. British Thoracic Society guideline for diagnostic flexible bronchoscopy in adults. BTS guidelines Thorax, v. 68, p. 1-44, Jul. 2013.

EFARED, B. et al. The diagnostic value of the bronchoalveolar lavage in interstitial lung diseases. J Negat Results Biomed., Mar. 2017.

FACCIO, A. A. Evolução da função pulmonar e do lavado bronco-alveolar em pacientes portadores de câncer de pulmão submetidos à radioterapia $e$ quimioterapia concomitantes. Ribeirão Preto: Universidade de São Paulo, 2004.

FERNANDO, S. M. et al. Diagnóstico de pneumonia associada à ventilação em pacientes adultos em estado crítico - uma revisão sistemática e meta-análise. Intensive Care Med., p. 1170-1179, abr. 2020.

FIÓRIO, C. E. et al. Prevalência de hipertensão arterial em adultos no município de São Paulo e fatores associados. Rev bras epidemiol., v.23, p. 1-13. 2020.

FLOR, L.S.; Campos, M.R. Prevalência de diabetes mellitus e fatores associados na população adulta brasileira: evidências de um inquérito de base populacional. Rev Bras Epidemiol., p.16-29. 2017.

FRYE, B.C. et al. The value of bronchoalveolar lavage for discrimination between healthy and diseased individuals. J. Intern. Med., v. 287, p. 54-65, Jan. 2020.

GRÜNEWALDT, A. et al. Evaluation zum möglichen Stellenwert der Bronchiallavagezytologie bei Erstdiagnose und Nachsorge des Lungenkarzinoms 
Possible Significance of Bronchoalveolar Lavage Cytology at Initial Diagnosis and Follow-up of Lung Cancer. Pneumologie, p. 106-110, Fev. 2017.

HELLYER, T. P. et al. Biomarker-guided antibiotic stewardship in suspected ventilator-associated pneumonia (VAPrapid2): a randomised controlled trial and process evaluation. Lancet Respir Med., v. 8, p. 182-191, Fev. 2020.

HOSPITAL DAS CLÍNICAS DA FACULDADE DE MEDICINA DE RIBEIRÃO PRETO. Protocolos operacionais. Ribeirão Preto, SP: HCFMRP, 2021.

ILANA, O. et al. Does molecular analysis increase the efficacy of bronchoalveolar lavage in the diagnosis and management of respiratory infections in hematooncological patients? International Journal of Infectious Diseases, Aarhus, p. 4853, Set. 2016.

INOMATA, T. et al. Neutrophil predominance in bronchoalveolar lavage fluid is associated with disease severity and progression of HRCT findings in pulmonary Mycobacterium avium infection. PLoS One, Rutgers Biomedical and Health Sciences. 2018.

INSTITUTO BRASILEIRO DE GEOGRAFIA E ESTATÍSTICA. Brasil em Síntese. Disponível em: https://brasilemsintese.ibge.gov.br/populacao/distribuicao-dapopulacao-por-sexo.html 30/05/2021. Acesso em: 07 Jun. 2021.

IU, X. et al. Indicadores para predição de positividade para Mycobacterium tuberculosis detectada com fluido de lavagem broncoalveolar. Infect Dis Poverty, Mar. 2018.

JACOMELLI, M. et al. Early complications in flexible bronchoscopy at a university hospital. J. Bras. Pneumol., v. 46, p. 1-6, Jun. 2020.

KAO, K. et al. Coinfecção e mortalidade em pacientes com síndrome de angústia respiratória aguda relacionada à pneumonia com lavagem broncoalveolar. Shock, v. 74, ed. 5, p. 615-620, Mai. 2017.

KIDO, T. et al. The utility of electron microscopy in detecting asbestos fibers and particles in BALF in diffuse lung diseases. BMC Pulm Med, Abr. 2017.

KISHABA, T. Evaluation and management of Idiopathic Pulmonary Fibrosis. Respiratory Investigation, v. 57, p. 300-311, Jul. 2019.

LEE, J. et al. Bronchoalveolar lavage (BAL) cells in idiopathic pulmonary fibrosis express a complex pro-inflammatory, pro-repair, angiogenic activation pattern, likely associated with macrophage iron accumulation. PLoS One. Gernot Zissel, Universitatsklinikum Freiburg, Abr. 2018. 
LI, Z.; LU, G.; MENG, G. Pathogenic Fungal Infection in the Lung. Front Immunol.,Jul. 2019.

LIU, et al. Indicators for prediction of Mycobacterium tuberculosis positivity detected with bronchoalveolar lavage fluid. Infect Dis Poverty, Mar. 2018.

LYON, S. M; ROSSMAN, M. D. Pulmonary Tuberculosis. American Society for Microbiology, In Tuberculosis and Nontuberculous Mycobacterial Infections, D. Schlossberg (ed.), p. 283-298, Jan. 2017.

MEYER, K. C. et al. An Official American Thoracic Society Clinical Practice Guideline: The Clinical Utility of Bronchoalveolar Lavage Cellular Analysis in Interstitial Lung Disease. American journal of respiratory and critical care medicine, v. 185, Jan. 2012.

MILLER, J.R. et al. Flexible Bronchoscopy. Clin Chest Med, Maryland Heights, v.39, p.1-16, Mar. 2018.

MILLER, R. et al. Hipersensibilidade Pneumonite: Uma Perspectiva de Membros da Sociedade de Patologia Pulmonar. Arch Pathol Lab Med., v. 1, n. 142, p. 120-126, 2018.

MLIKA, M. et al. The efficacy of bronchial washings in diagnosis of lung carcinoma. Pathologica, p.175-6, Ago. 2012.

NOVOSADOVA, E. et al. Comparison of lymphocyte immune phenotypes in bronchoalveolar lavage of non-smoking patients with sarcoidosis and other interstitial lung diseases. J Thorac Dis., p. 2287-2296, Jun. 2019.

Organização Mundial da Saúde. Global tuberculosis report 2018. In. Genebra, Suíça: OMS. 2018.

PATEL, P.H.; BHIMJI, S.S. Lavagem broncoalveolar. StatPearls, Filadélfia, 2017. Disponível em: www.ncbi.nlm.nih.gov/books/NBK430762/\#_NBK430762_pubdet.. Acesso em: 28 abr. 2018.

PETROSYAN, F.; CULVER, D. A.; REDDY, A. J. Papel do lavado broncoalveolar no diagnóstico de exacerbações agudas de fibrose pulmonar idiopática: um estudo retrospectivo. BMC Pulm Med, n. 70, Jul. 2015.

POTHAL, S. et al. Diagnostic efficacy of broncho-alveolar lavage carcino-embronic antigen in carcinoma of lung. J Family Med Prim Care, v.8, p.1725-1729, Mai. 2019.

PRASAD, J. D. et al. The interstitial lung disease multidisciplinary meeting: A position statement from the Thoracic Society of Australia and New Zealand and the Lung Foundation Australia. Respirology Nedlands, p.1459-1472, Set. 2017.

QUINTON, L. J.; WALKEY, A. J.; MIZGERD, J. P. Integrative Physiology of Pneumonia. Physiol Rev., p.1417-1464, Jul. 2018. 
RADHA, S. et al. Diagnostic utility of bronchoalveolar lavage. J Cytol., v. 31, p. 136138, Jul. 2014.

RADHAKRISHNA, N. et al. A Comparison of Techniques for Optimal Performance of Bronchoalveolar Lavage. J Bronchology Interv Pulmonol, Melbourne, p.300305, Out. 2015.

RAGHU, G. et al. Diagnosis of Hypersensitivity Pneumonitis in Adults. An Official ATS/JRS/ALAT Clinical Practice Guideline. Am J Respir Crit Care Med., p. 36-69, Ago. 2020. Erratum in: Am J Respir Crit Care Med., p. 150-151, Jan. 2021.

RIVERA-ORTEGA, P.; MOLINA-MOLINA, M. Interstitial Lung Diseases in Developing Countries. Annals of Global Health, p. 1-14, Jan. 2019.

SALISBURY, M. L. et al. Diagnosis and Treatment of Fibrotic Hypersensitivity Pneumonia. Where We Stand and Where We Need to Go. Am J Respir Crit Care Med., p. 690-699, Set. 2017.

SARTORELLI, P. et al. Cytological analysis of bronchoalveolar lavage fluid in asbestos-exposed workers. Med Lav., v. 111, n. 5, p. 379-387, Out. 2020.

SCHABATH, M. B.; COTE, M. L. Cancer Progress and Priorities: Lung Cancer. Cancer Epidemiol Biomarkers Prev., p.1563-1579, Out. 2019.

SCHABEL, R. M. et al. Clinical course and complications following diagnostic bronchoalveolar lavage in critically ill mechanically ventilated patients. BMC Pulmonary Medicine, Londres, v.29, p.1-9, 2015.

SGALLA, G. et al. Idiopathic pulmonary fibrosis: pathogenesis and management. Respiratory Research, Feb. 2018.

SHI, J. et al. Pathogenic microorganism detection in AIDS patients using bronchoalveolar lavage fluid. Int J Clin Exp Pathol, p.1727-1732, Jul. 2020.

SMITH, J. A.; KAUFFMAN, C. A. Pulmonary fungal infections. Respirology, v. 17, p. 913-926, Ago. 2012.

SOTO-GOMEZ, N.; PETERS, J. I.; NAMBIAR, A. M. Diagnosis and Management of Sarcoidosis. Am Fam Physician, p. 840-850, Mai. 2016.

SUÁREZ, I. et al. The Diagnosis and Treatment of Tuberculosis. Dtsch Arztebl Int., p. 729-735, Out. 2019.

SZTURMOWICZ, M. et al. Correlation of bronchoalveolar lavage lymphocyte count with the extent of lung fibrosis and with plethysmographic lung volumes in patients with newly recognized hypersensitivity pneumonitis. Central European Journal of Immunology, p. 276-282, 2020. 
TOMAR, V. et al. Comparative study of bronchoalveolar lavage, bronchial brushing, and FNAC in diagnosing malignant neoplasms of lungs. J Cytol., p. 210-213, Out./Dez. 2016.

TSAI, C. M. et al. Diagnostic value of bronchoalveolar lavage in children with nonresponding community-acquired pneumonia. Pediatr Neonatol, p. 430-436, Out. 2017.

VINCENT, J. et al. Prevalence and Outcomes of Infection Among Patients in Intensive Care Units in 2017. JAMA, v. 323, p. 1478-1487, Abr. 2020.

WATTS, M. M.; GRAMMER, L. C. Hypersensitivity pneumonitis. Allergy Asthma., p. 425-428, Nov. 2019.

YAGUCHI, T. O gênero Aspergillus. Med Mycol J., p.193-197, 2011.

ZHANG, Y. et al. Upregulation of E-cadherin in bronchoalveolar lavage fluid-derived exosomes in patients with lung cancer. Thoracic Cancer, p. 41-47, Jan. 2020.

ZHONG, C. H. et al. Performance evaluation of detecting circulating tumor cells and tumor cells in bronchoalveolar lavage fluid in diagnosis of peripheral lung cancer. $\mathbf{J}$ Thorac Dis., v. 10, Abr. 2018. 
ANEXO 
ANEXO A - Modelo de solicitação para realizações do LBA

\section{SEÇÃO DE PNEUMOLOGIA DO H.C.R.P \\ LAVADO BRONCOALVEOLAR №}

Data:

Nome:

Reg.H.C

Data de nascimento:

Médico solicitante:

Setor HC: [ ] Internado

Enfermaria:

[ ] Ambulatório

Qual?:

[ ] UE

[ ] UTI

Diagnóstico clínico

Radiografia de tórax:

Hipóteses diagnósticas:

LBA anterior: [ ] Sim

[ ] Não

Em uso de corticoides: [ ] Sim

[ ] Não

Há quanto tempo?:

Dose:

Em uso de quimioterápicos: [ ] Sim [ ] Não

Quais:

Fumante: [ ] Sim [ ] Não Carga:.................................Ex - fumante: ........anos

Profissão:

Achados da broncoscopia: [ ] Dentro da normalidade [ ] Bronquite crônica
[ ] Tumor
[ ] Processo inflamatório agudo

Biópsia transbronquica: [ ] Sim

[ ] Não

Localização do LBA:

Quantidade de soro fisiológico instilada:

.ml Retorno:

Envio de parte do LBA para outros laboratórios: [ ] Sim

[ ] Não

Quais:

Figura 2. Modelo de solicitação para realizações do LBA 
APÊNDICE 


\section{APÊNDICE A - Modelo do banco de dados para inserção das variáveis dos indivíduos da pesquisa}

\begin{tabular}{|l|l|l|l|l|l|l|l|l|l|l|}
\hline \multicolumn{3}{|c|}{ Identificação do indivíduo } & \multicolumn{3}{c|}{ Características } & \multicolumn{3}{c|}{} \\
\hline Registro & Número da pesquisa & Data do exame & Sexo & Data de nascimento & Idade & Cor & \multicolumn{2}{c|}{ Tabagismo } & Profissão \\
\hline & & & & & & & & $\begin{array}{c}\text { Não tabagista } \\
\text { Tabagista }\end{array}$ & \\
& & & & & & & & \\
Ex-tabagista & Carga & \\
\hline
\end{tabular}

\begin{tabular}{|c|c|c|c|c|}
\hline \multicolumn{2}{|c|}{ Características Pessoais } & Situação hospitalar & Quadro Clínico & Radiografia de tórax \\
\hline Exposição & O2 Domiciliar & & & \\
Pássaros, pena, tabagismo passivo, fogào à lenha, atividades ocupacionais, & & Ambulatorial & & \\
drogas potencionalmente tóxicas, drogas ilicitas, & Presente & Enfermaria & & \\
quimioterapia, radioterapia ou outros & ou ausente & Terapia intensiva & & \\
\hline
\end{tabular}

\begin{tabular}{|c|c|c|c|c|c|c|}
\hline Tomografia de tórax & Biópsia transbronquica & Citologia & Cultura-Microbiologia & \multicolumn{3}{|c|}{ Micologia } \\
\hline & & & & Baciloscopia para TB & Cultura & Exame direto para $\mathrm{TH}$ \\
\hline & & & & & & \\
\hline & & & & & & \\
\hline
\end{tabular}

\begin{tabular}{|l|l|l|l|l|l|}
\hline Achados da broncoscopia & Hipótese diagnóstica & Doenças Associadas & \multicolumn{2}{|c|}{ Aspecto LBA } \\
\hline & & & Volume inicial do LBA & Volume de retorno do LBA & \% do volume \\
\cline { 5 - 6 } & & & & & \\
& & & & & \\
\hline
\end{tabular}

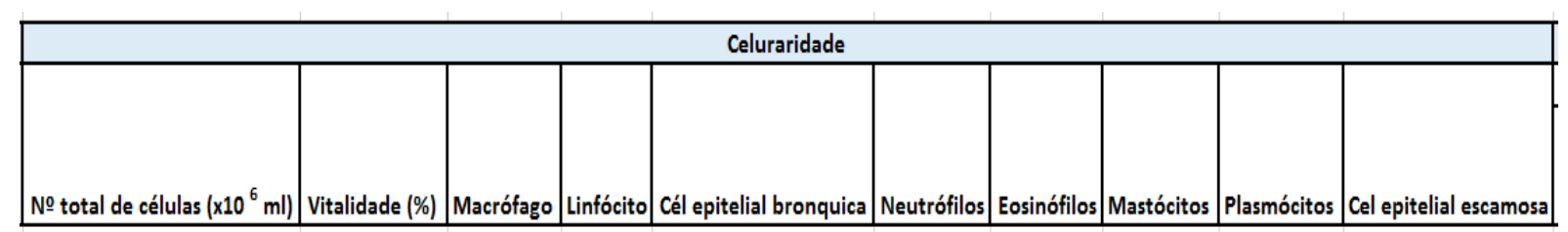

\begin{tabular}{|c|c|c|c|c|c|c|c|c|c|}
\hline \multicolumn{2}{|c|}{ Coloração } & \multicolumn{2}{|c|}{ Demais exames para o diagnóstico } & \multirow[t]{2}{*}{ Intercorrências } & \multirow[t]{2}{*}{ Localização do LBA } & \multicolumn{4}{|c|}{ Resolução } \\
\hline Ziehl Neelsen & Toluidina & Escarro & Cirurgica pulmonar & & & Conduta antes do LBA & Conduta após LBA & Efeito diagnóstico & Observações \\
\hline & & & & & & & & & \\
\hline & & & & & & & & & \\
\hline
\end{tabular}

Figura 3. Modelo do banco de dados para inserção das variáveis dos indivíduos da pesquisa 